Revue des patrimoines

$12 \mid 2009$

Le patrimoine religieuX des $\mathrm{XIX}^{\mathrm{e}}$ et $\mathrm{XX}$ siècles $-2^{\mathrm{e}}$ partie

\title{
Sainte-Bernardette du Banlay, Nevers
}

Christophe Joly, Orlane Brault et Paul Barnoud

\section{OpenEdition}

1 Journals

Édition électronique

URL : http://journals.openedition.org/insitu/6444

DOI : 10.4000/insitu.6444

ISSN : 1630-7305

Éditeur

Ministère de la culture

Référence électronique

Christophe Joly, Orlane Brault et Paul Barnoud, « Sainte-Bernardette du Banlay, Nevers », In Situ [En ligne], 12 | 2009, mis en ligne le 03 novembre 2009, consulté le 19 avril 2019. URL : http:// journals.openedition.org/insitu/6444; DOI : 10.4000/insitu.6444

Ce document a été généré automatiquement le 19 avril 2019

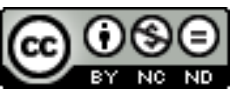

In Situ Revues des patrimoines est mis à disposition selon les termes de la licence Creative Commons Attribution - Pas d'Utilisation Commerciale - Pas de Modification 4.0 International. 


\title{
Sainte-Bernardette du Banlay, Nevers
}

\author{
Christophe Joly, Orlane Brault et Paul Barnoud
}

1 Cet article est le fruit des recherches effectuées par Christophe Joly sur l'histoire de Sainte-Bernadette du Banlay et de l'étude préalable à la restauration menée par Paul Barnoud assisté, pour la partie documentaire, par Orlane Brault ${ }^{1}$.

\section{Genèse de la construction}

2 À Nevers, dès 1930, les lieux de culte manquent, notamment dans le quartier du Banlay qui voit surgir de terre de nombreux pavillons dus à la loi Loucheur. En 1936, est édifié un nouveau lieu de culte pour accueillir les paroissiens qui affluent. Cet édifice est une simple chapelle que les institutions religieuses dédient à Bernadette. L'architecte, Georges-Théodore Renaud, un Versaillais, venait de réaliser deux séminaires et l'église de Bethléem à Clamecy, dans le nord du département de la Nièvre. Cette chapelle SainteBernadette est consacrée en $1938^{2}$.

3 À partir des années 1950, les pavillons côtoient une banlieue faite de tours et de barres en béton qui sont implantées sur vignes et jardins. Ces habitations sont construites dans la logique de cette époque et du développement de l'habitat social. À Nevers, comme dans de nombreuses villes de France, l'exode rural provoque l'accroissement de la population. Le quartier se développe. Les écoles primaires, collège, lycée et même une école normale surgissent de terre. Bientôt, l'offre religieuse devient insuffisante pour ce quartier.

C'est dans ce contexte de nécessité qu'est programmée la construction de l'église SainteBernadette du Banlay. L'idée directrice reposait sur la création d'une église capable d'accueillir les nouveaux paroissiens, et de s'adapter aux usages de son époque.

5 En effet, les années 1960 sont une période de réorganisation institutionnelle et de refonte spirituelle pour l'Église de Rome. Le concile Vatican II, ouvert par Jean XXIII, essaye de restaurer la proximité entre les serviteurs de Dieu et les fidèles. Ce concile demande à l'officiant de célébrer la messe en se plaçant face à l'assistance. Par ailleurs, les 
théologiens alors réunis repensent le rôle de la paroisse, qui doit devenir un lieu de rencontre et d'accueil. Enfin, le vocabulaire est lui aussi revisité pour que la rencontre entre l'église et les fidèles se fasse dans l'entente et la confiance; on parle alors de complexe paroissial et non plus d'église. Cette modification du champ lexical vise à introduire l'idée que les officiants et les paroissiens ne forment qu'une seule et même entité au sein de la paroisse.

Ces mutations idéologiques et institutionnelles influencent profondément les promoteurs du projet de la nouvelle église au Banlay. Dans ces préliminaires au projet, il est possible de sentir le souffle des idées de Vatican II. Les éléments de définition de ce que devra être la future église insistent sur « les notions de lisibilité, de participation, de déplacement des fidèles et de l'officiant ${ }^{3}$.»

7 C'est au cours de l'année 1963 que se mettent en place les lignes directrices de la construction de l'église Sainte-Bernadette du Banlay. Les premières bases de réflexion pour l'érection d'une nouvelle paroisse sont jetées ${ }^{4}$. Par ailleurs, le diocèse lance un concours d'architecture pour construire une église dans cette nouvelle paroisse. Mais il est vrai que le chantier est depuis longtemps un sujet de réflexion pour le curé de la paroisse et l'évêque, qui, depuis début 1960, cherchent un terrain pour l'église. Un premier terrain est repéré à la jonction du boulevard Saint-Exupéry, de la rue de Barcelone et de la rue de Parigny, mais faute d'accord, ce n'est qu'en 1962 que l'évêque et ses collaborateurs envisagent d'édifier une église rue du Banlay ${ }^{5}$. L'évêque charge l'abbé Bourgoin, prêtre de la chapelle Sainte-Bernadette et futur curé de la paroisse SainteBernadette, de rédiger le programme détaillé de la future église. Claude Parent dira: «C'est l'Abbé Bourgoin qui nous donna le magnifique programme en forme de circulation liturgique. Sans lui, jamais l'église Sainte-Bernadette n'aurait été ce qu'elle est.» $\mathrm{Ce}$ programme sert de guide pour les candidats au concours d'architecture ouvert par le diocèse. C'est Odette Ducarre, amie de Claude Parent et de Paul Virilio, qui, la première, prend connaissance du concours et permet au groupe Architecture Principe de s'y présenter. Au concours, qui se déroule en décembre $1963 \mathrm{chez}$ Mgr Vial, trois équipes d'architectes postulent:

- l'architecte François Lebas;

- l'architecte Jean Willerwal;

- le groupe Architecture Principe qui rassemble Claude Parent, Paul Virilio et des artistes (verriers, sculpteurs).

8 Le 28 août 1965, les articles qui créent la paroisse Sainte-Bernadette et qui prévoient l'édification d'une église sont publiés.

\section{Étapes et évolution du projet d'Architecture Principe}

Claude Parent et Paul Virilio veulent que l'église constitue une protection, un abri et qu'elle soit indépendante de l'urbanisation future du quartier, car ils savent bien, comme pour toutes les églises, qu'elle va être bientôt encerclée par des constructions diverses et multiples. La coupe longitudinale de l'édifice représente une forme de cœur. 
Figure 1

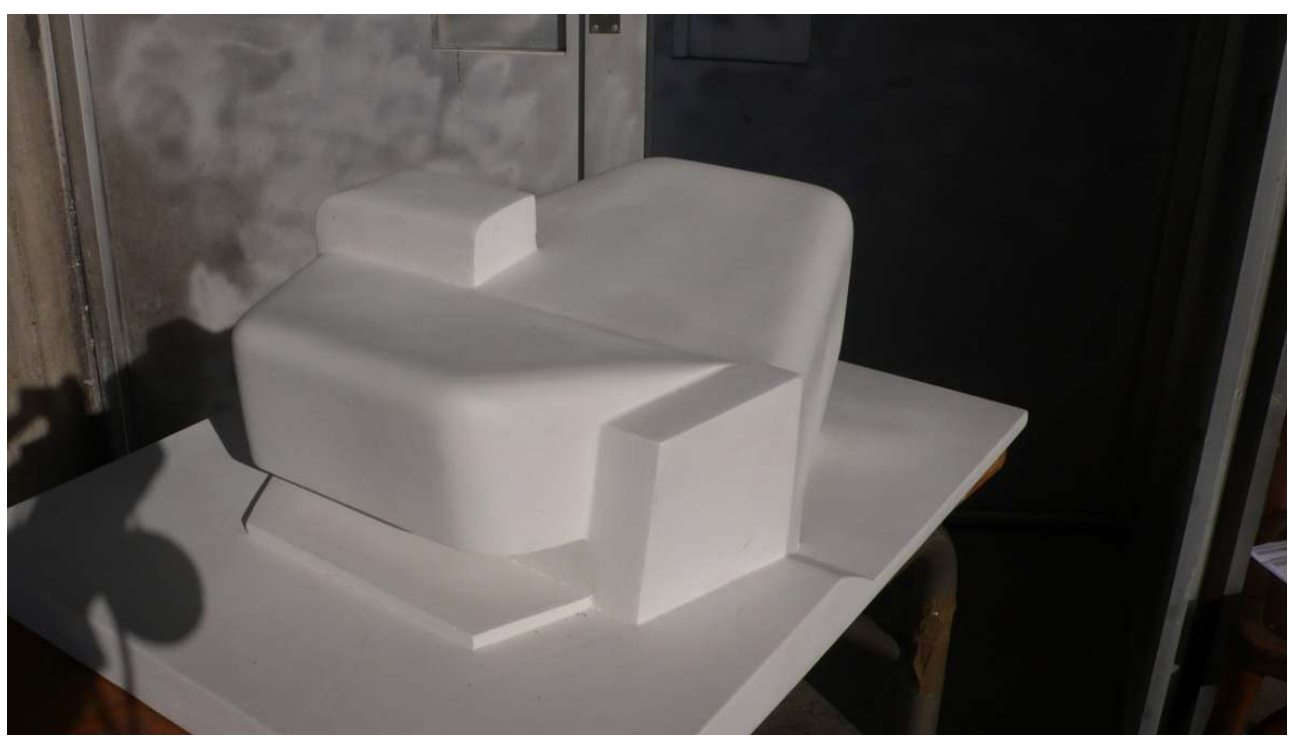

Reproduction de la maquette du projet, avant l'extension du lanternon. Phot. Paul Barnoud.

(c) Atelier Cairn architectes.

Pour des raisons économiques, une modification importante est apportée aux plans initiaux. La capacité de l'église est réduite de huit cents à six cents places. Cette réduction de la surface se fait en gardant la hauteur originale du projet de l'église. Les architectes

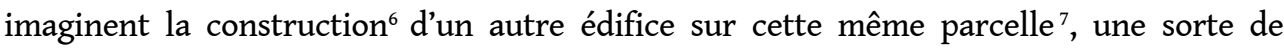
campanile, détaché de l'église, qui aurait eu la fonction de presbytère. Cette tour fonctionnant comme un signal devait se composer de deux étages. Par ailleurs, le projet, qui dès le départ propose la collaboration d'artistes pour la création des éléments mobiliers, est aussi amputé de la réalisation de la tapisserie de Michel Carrade. Celle-ci devait mesurer $4 \mathrm{~m}$ sur 2,50 $\mathrm{m}$ et être réalisée par la manufacture des Gobelins. Mais, comme les moyens manquent, le projet de cette œuvre qui devait prendre place au pied de l'escalier central ${ }^{8}$ est abandonné. (fig. $\mathbf{n}^{\circ} \mathbf{1}$ )

\section{La construction}

11 La Semaine religieuse, le bulletin d'information du diocèse, qui avait alerté les chrétiens sur la nécessité de créer une nouvelle paroisse au nord de Nevers, motive les esprits et les personnes en faveur de ce projet. Une association est créée pour mobiliser les paroissiens et c'est elle qui se charge de réunir le budget pour la construction. Ainsi, l'église est édifiée par la Société des nouvelles églises nivernaises.

12 Le 28 septembre 1964, le permis de construire est déposé par l'association diocésaine de Nevers. Au printemps 1965, passé le délai réglementaire, le chantier commence. Les travaux sont menés sans interruption pendant vingt-trois mois.

13 Mgr Vial impose aux architectes d'associer à leur équipe un architecte local, M. Sonnet ${ }^{9}$, qui a en charge la mission d'exécution. Mais cette collaboration est de courte durée, puisque cet associé est déchargé de ses fonctions dès janvier $1965^{10}$, à la suite de désaccords au sujet de la consultation des entreprises. 
14 Trente entreprises répondent à l'appel d'offre pour le gros œuvre, mais apparemment aucune n'est en mesure de respecter le budget, ni même les plans d'Architecture Principe. Ainsi, ce sont les architectes qui soumettent l'idée de travailler avec un entrepreneur parisien, E.T.E.B., avec lequel ils ont l'habitude de collaborer. E.T.E.B., entreprise technique d'équipement du bâtiment et travaux publics, entreprise des frères Dupuch, était établie à proximité de Paris. Le contrat de soumission de travaux est signé le 11 janvier $1965^{11}$.

15 L'ensemble de l'édifice, extérieur comme intérieur, est traité en béton brut. Les coffrages, particulièrement soignés, sont réalisés au moyen de planches brutes. À l'origine, une isolation par flocage était prévue à l'intérieur de l'édifice, mais elle n'a pas été réalisée, à la grande satisfaction de Claude Parent qui préférait que l'église reste en béton apparent.

Le chantier débute en avril 1965. C'est en mars 1966 que le gros-œuvre est achevé. Il était alors possible de se consacrer aux travaux de finition et au mobilier. Les vitraux d'Odette Ducarre sont exécutés en verre antique selon la technique traditionnelle de vitrail. La cloche vient de Mers el-Kébir ${ }^{12}$ car à cette période il était possible de récupérer le mobilier des églises du Maghreb transformées en mosquées.

17 L'église est inaugurée en 1966, soit un siècle après la venue de Bernadette à Nevers. Le 6 décembre 1966, l'église est consacrée par Monseigneur Streff, évêque de Nevers et successeur de Mgr Vial, en présence de l'abbé Bourgoin, curé de la paroisse. La réception définitive des travaux a lieu le 8 décembre $1967^{13}$. Le 20 décembre 1991, l'église est cédée à la Ville de Nevers pour un franc symbolique.

L'édifice est classé au titre des monuments historiques le 25 mai 2000, à la suite d'une inscription à l'inventaire supplémentaire des monuments historiques datant du 13 janvier de la même année.

En 2005, le Conseil régional inscrit l'édifice parmi les «Joyaux architecturaux du 20e siècle $^{14}$. » (fig. $\left.\mathbf{n}^{\circ} 2, \mathbf{n}^{\circ} 3\right)$ 
Figure 2

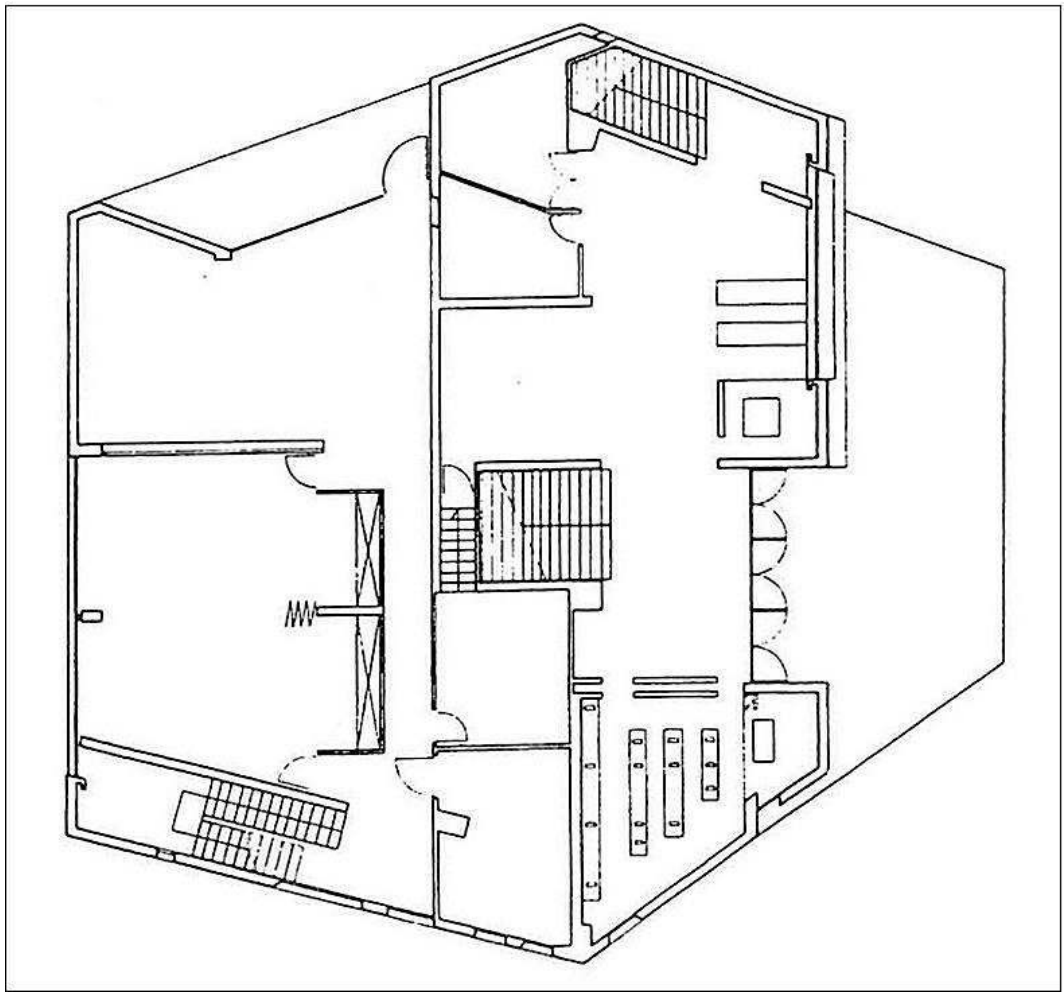

Plan du rez-de-chaussée. Plan Claude Parent.

(c) Collection de l'abbé Bourgoing.

Figure 3

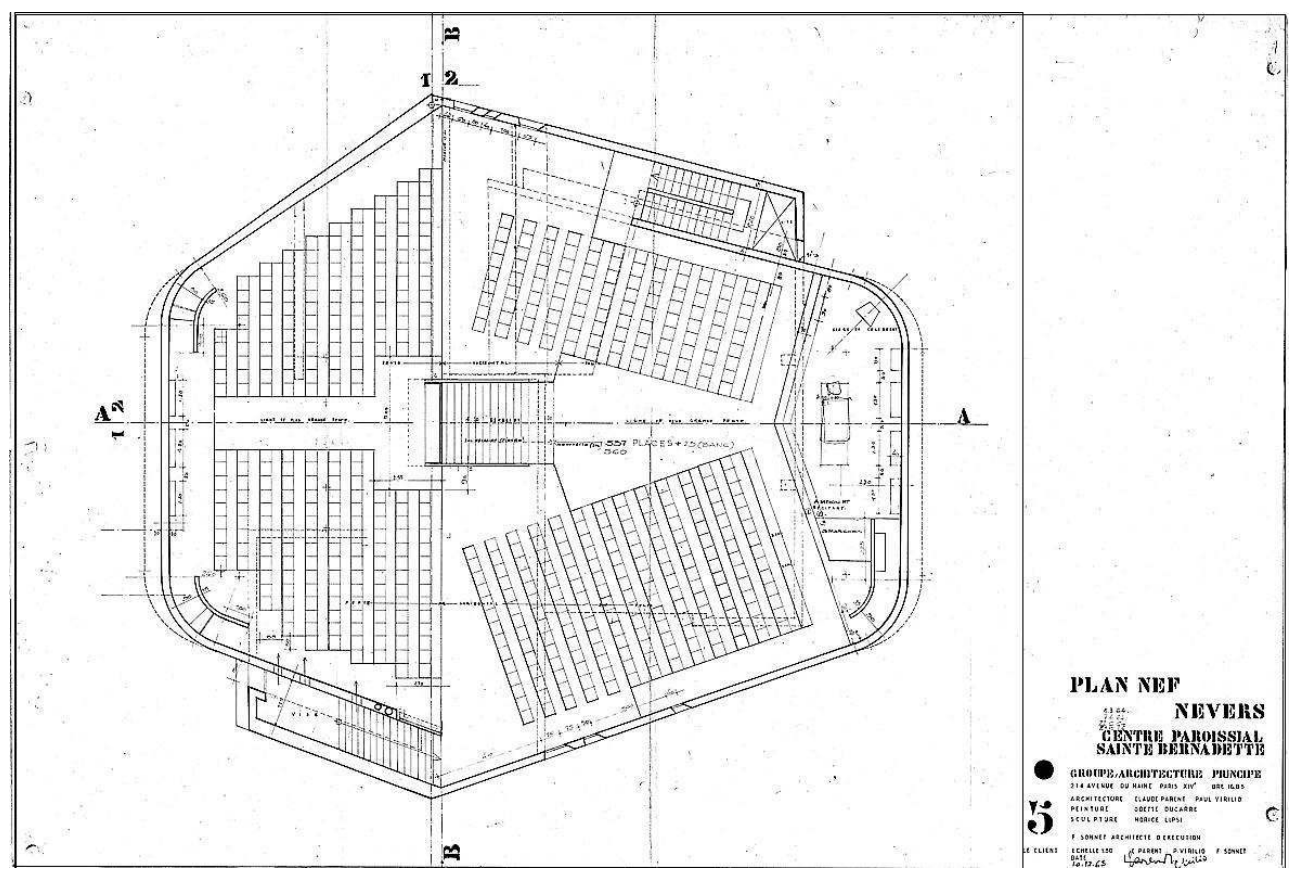

Plan de la nef. Plan Claude Parent.

(c) Collection de l'abbé Bourgoing. 


\section{Des idées fortes à l'origine du projet}

21

édifice témoigne de la fonction oblique, dont Claude Parent et Paul Virilio ont fait le fondement d'une nouvelle architecture. Paul Virilio a imprimé sa marque de fabrique dans l'aspect blockhaus de cette construction. «L'église Sainte-Bernadette de Nevers est un édifice témoin. Témoin d'un siècle impitoyable, qui a accumulé les drames, les guerres les plus tragiques de l'histoire ${ }^{15}$.» "L'église de Nevers s'apparente donc à ce que l'on dénommait à l'époque romane une église fortifiée, autrement dit un lieu sacré qui symbolise, dans sa simplicité, la protection de la vi ${ }^{16}$. » Érigée après le traumatisme du second conflit mondial et en plein cœur de la période de guerre froide, l'église du Banlay a tout du «bunker ${ }^{17}$ » et surtout d'une «architecture répulsive ». Virilio parle d'espace « cryptique $»^{18}$.

La forme générale de l'édifice repose sur des idées originelles très fortes :

- le vocabulaire des bunkers du mur de l'Atlantique nord, largement étudié par Paul Virilio : massivité de l'édifice, béton brut, aspect monolithique et emploi d'arcs déprimés ; - les deux plans inclinés de la nef comme application directe des théories de Claude Parent sur la fonction oblique ;

- la métaphore de la grotte, et son vocabulaire de l'architecture cryptique, allusion à la grotte de Lourdes.

(fig. $n^{\circ} 4, n^{\circ} 5$ )

Figure 4

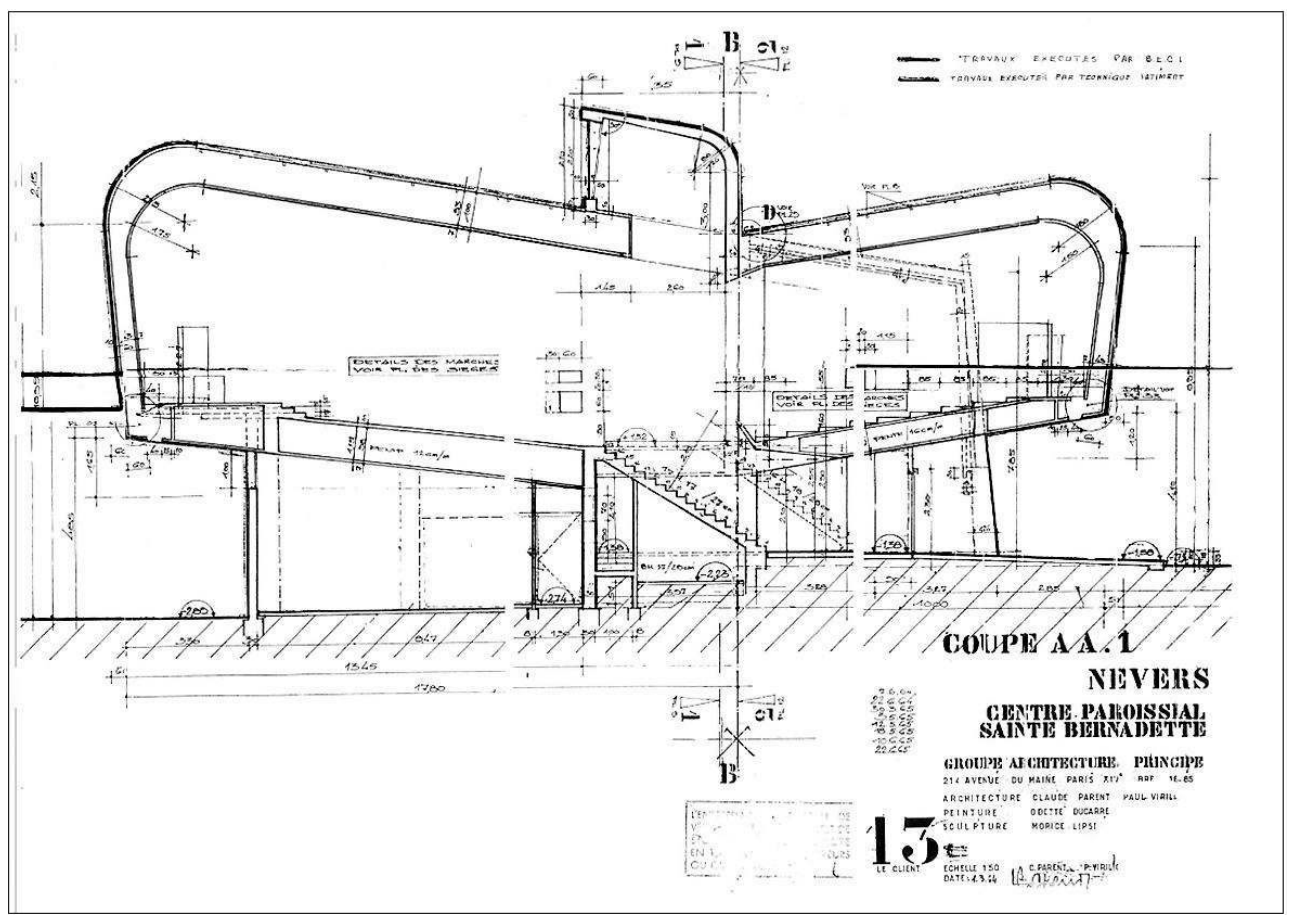

Coupe longitudinale. Plan Claude Parent.

(c) Collection de l'abbé Bourgoing. 


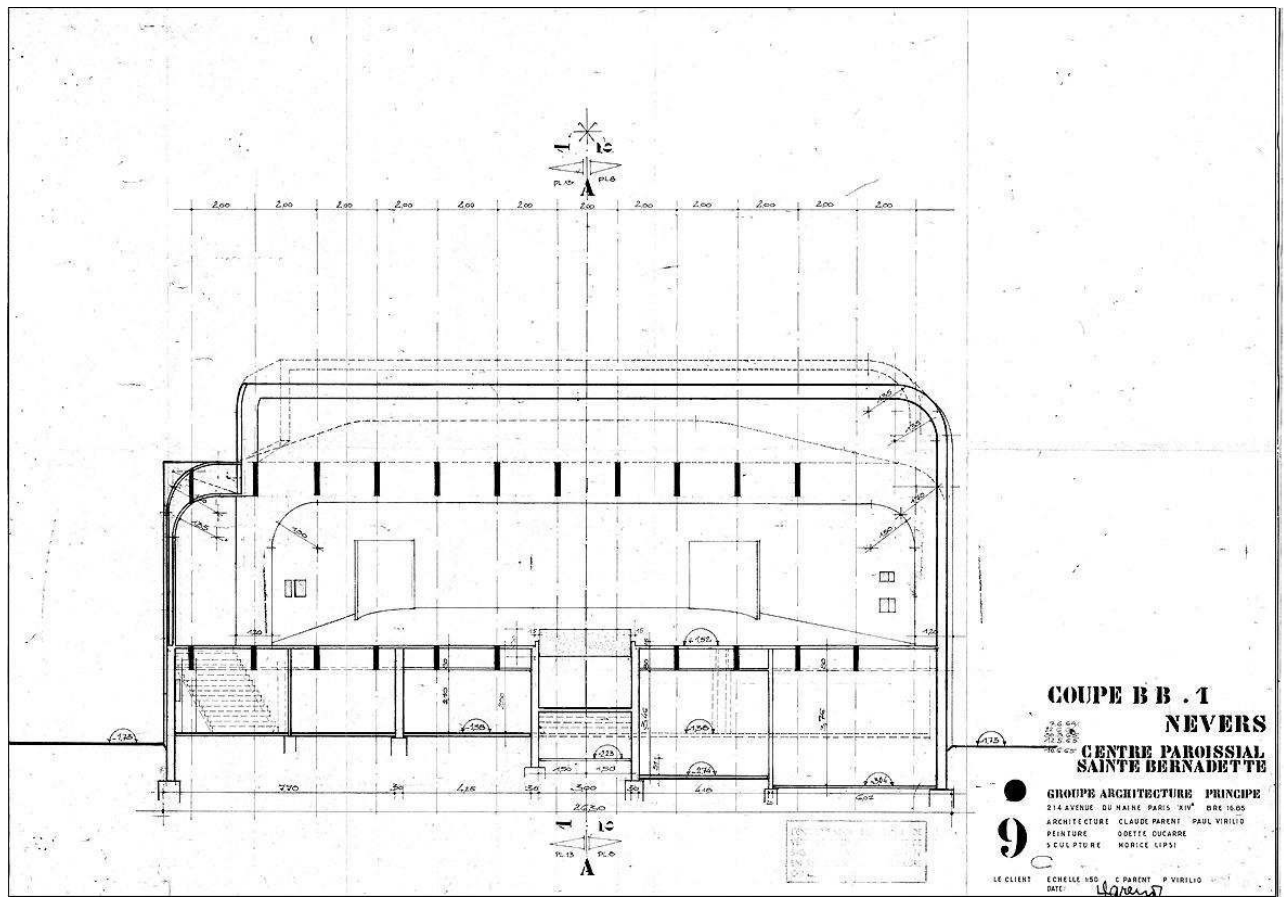

Coupe transversale. Plan Claude Parent

(c) Collection de l'abbé Bourgoing.

\section{Le parti architectural et constructif}

Le concept fondateur du projet réside dans la forme générale de l'édifice : deux plans inclinés surélevés qui viennent recouvrir les locaux de service du rez-de-chaussée. Deux coques surélevées couvrent ces plans inclinés et adoptent le profil d'arcs déprimés caractéristique de l'architecture militaire des bunkers.

La résolution technique de la structure porteuse qui en découla n'est que la conséquence d'une forme voulue et prédéterminée.

\section{Volumes extérieurs}

De l'extérieur, l'édifice est austère, rude. L'église donne une impression générale de masse. Les deux coques de béton, en porte-à-faux, s'imbriquent l'une dans l'autre en se décalant par rapport à l'axe longitudinal. L'apparence générale est un édifice monolithique, inspiré du rocher, comme un gros caillou, seulement percé de fentes de lumière, horizontales ou verticales, dans les espaces dégagés par la translation des deux blocs. Le béton, brut de décoffrage, a été travaillé pour laisser apparaître des traces de banches régulières, en harmonie avec la forme bombée de l'édifice. Les façades, en béton brut, sont diversement ajourées. Les abords sont traités en cailloux de ballast cadrant le monument sur un socle minéral.

L'église résiste à la banalité ambiante. (fig. $n^{\circ} 6, n^{\circ} 7, n^{\circ} 8, n^{\circ} 9$ ) 
Figure 6

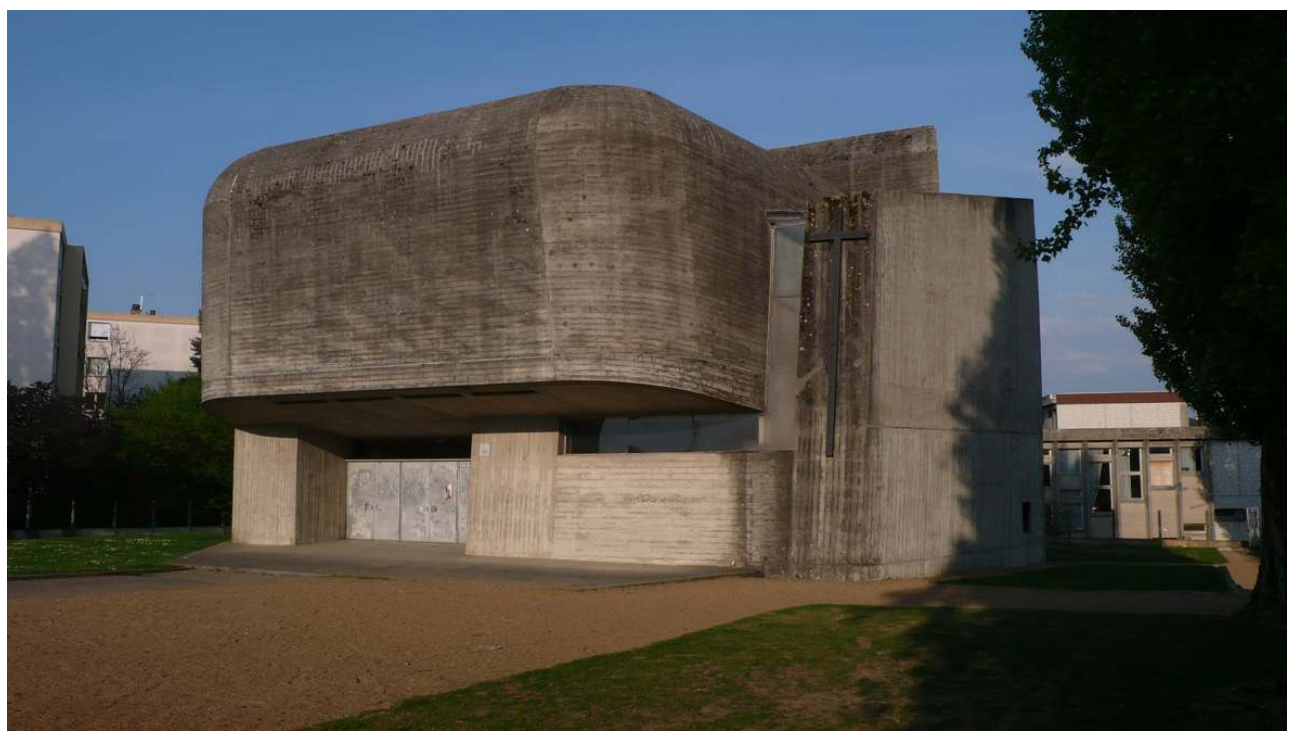

Façades sud et ouest. Phot. Paul Barnoud.

(c) Atelier Cairn architectes.

Figure 7

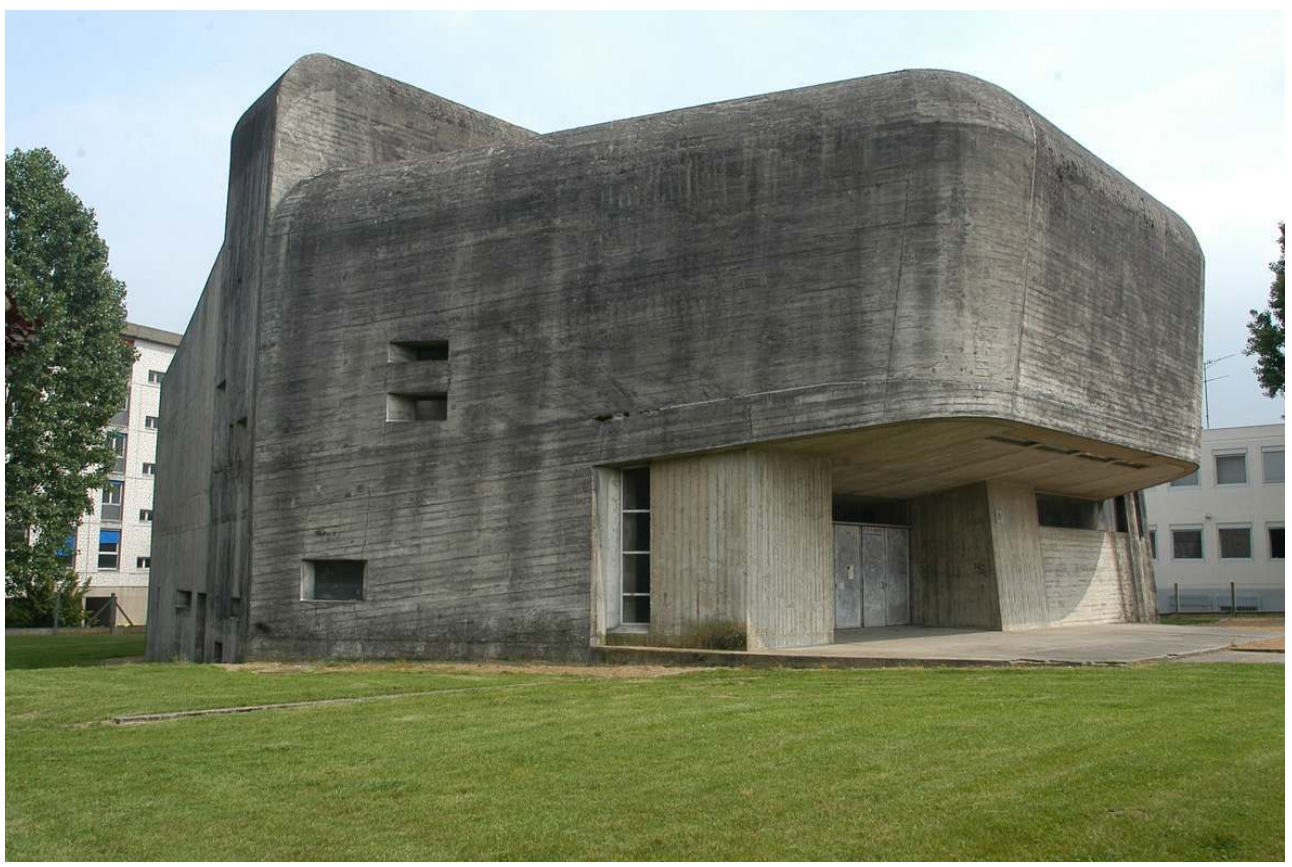

Façades nord et ouest. Phot. Paul Barnoud.

(c) Atelier Cairn architectes. 


\section{Figure 8}

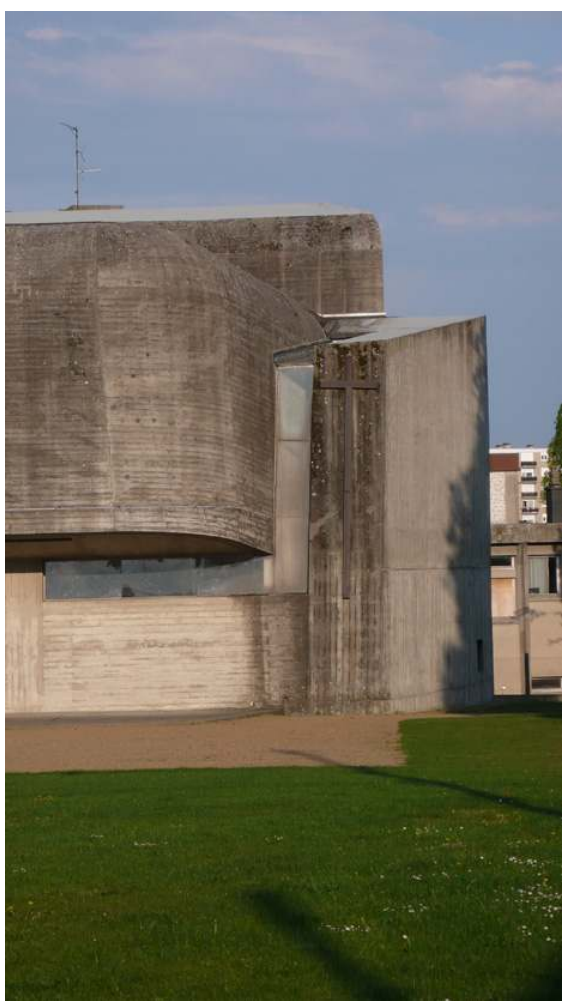

Fente de lumière au contact entre les deux coques de béton. Phot. Paul Barnoud (c) Atelier Cairn architectes. 
Figure 9

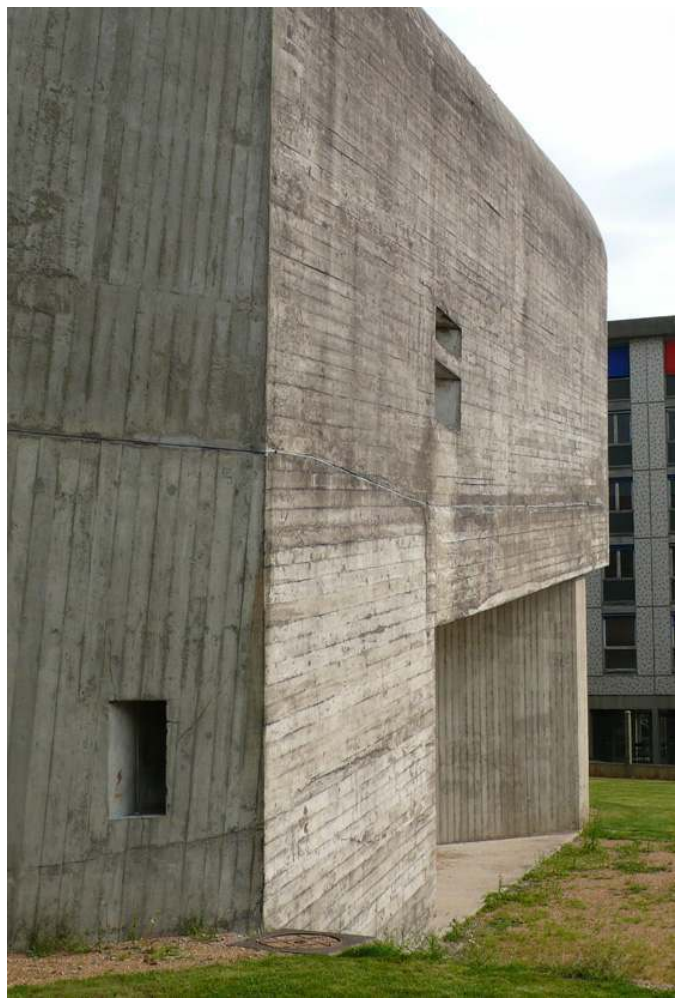

Façade sud. Phot. Paul Barnoud.

(c) Atelier Cairn architectes.

\section{Volumes intérieurs}

Contrairement à l'extérieur, l'intérieur présente un aspect accueillant, dense et protecteur. Claude Parent et Paul Virilio rompent avec la tradition du plan en croix traditionnel, en dessinant un plan en hexagone irrégulier.

Deux coques en demi-hexagones s'enchâssent l'une dans l'autre, ce qui permet d'implanter des escaliers secondaires, dans les fentes latérales, de part et d'autre de la nef.

L'accès principal à l'étage s'effectue par un large escalier d'une seule volée au centre de la nef.

L'utilisation du vocabulaire de l'architecture cryptique traduit ici l'évocation de la grotte, comme métaphore de la grotte de Lourdes : faible lumière, présence massive des coques de béton brut, formes arrondies, échappées visuelles ascendantes et plongeantes...

Le rez-de-chaussée de l'édifice épouse la pente naturelle du terrain. Il est fractionné en deux parties décalées d'un demi-niveau. Le niveau bas accueille la salle de réunion et la salle de catéchisme, tandis que le degré supérieur du rez-de-chaussée se compose de la chapelle de semaine, des fonts baptismaux, de la sacristie, du hall d'accueil et des escaliers latéraux. Au demi-niveau supérieur, le rez-de-chaussée est traité en plan libre avec très peu de portes. Le grand hall d'entrée est délimité par des voiles de béton continus. La chapelle de semaine, à gauche en entrant, de petite taille, est séparée du hall 
d'accueil par une double cloison de béton. Enfin, le baptistère, sur la droite, s'ouvre largement sur le hall d'entrée, trouvant refuge dans un de ses renfoncements.

32 À l'étage, le volume accueille la nef, l'autel et les confessionnaux avec les deux plans inclinés, venant à la rencontre l'un de l'autre, tel un $\mathrm{V}$, à l'aplomb du lanternon. (fig. $\mathrm{n}$ $\left.\circ 10, n^{\circ} 11, n^{\circ} 12, n^{\circ} 13, n^{\circ} 14, n^{\circ} 15\right)$

Figure 10

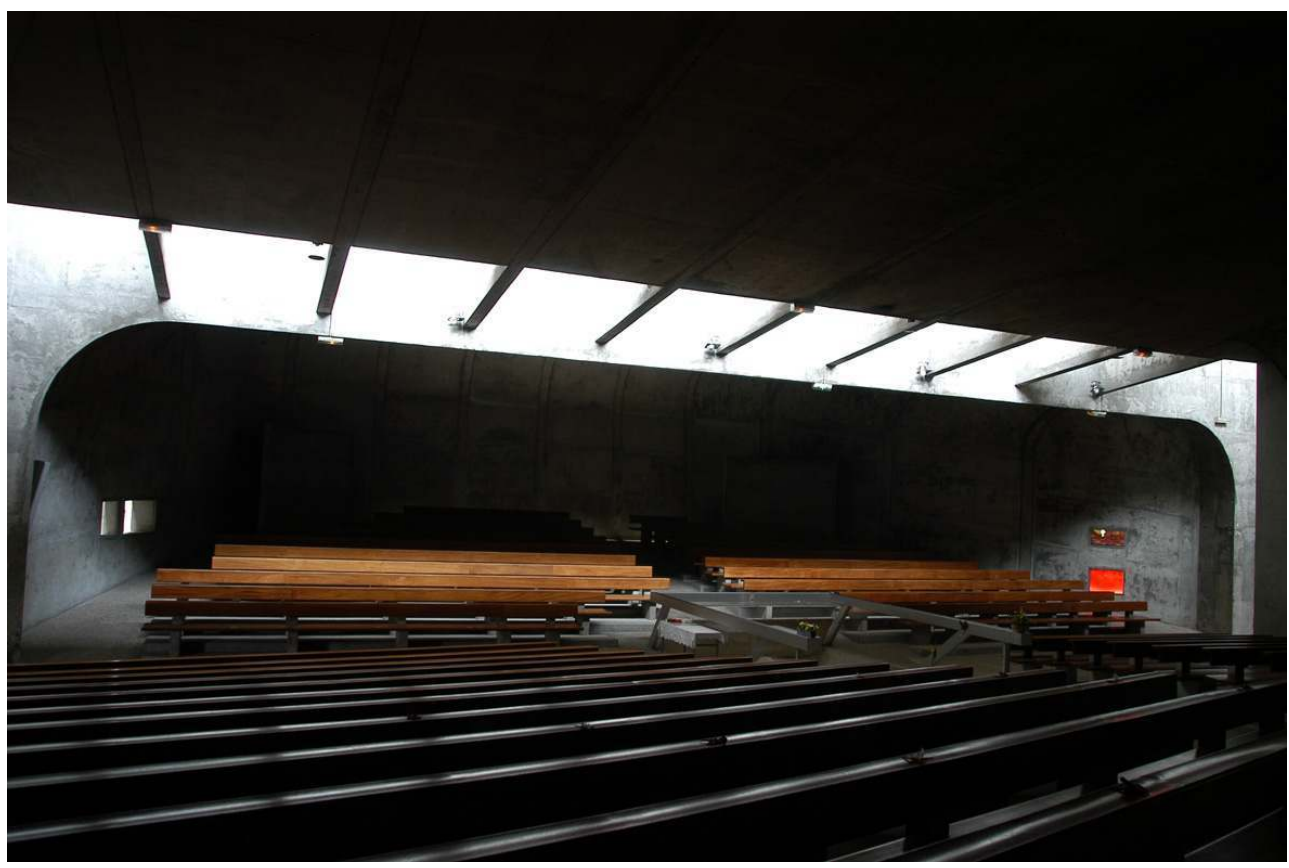

La nef vue depuis le chœur. Phot. Paul Barnoud.

(c) Atelier Cairn architectes.

Figure 11

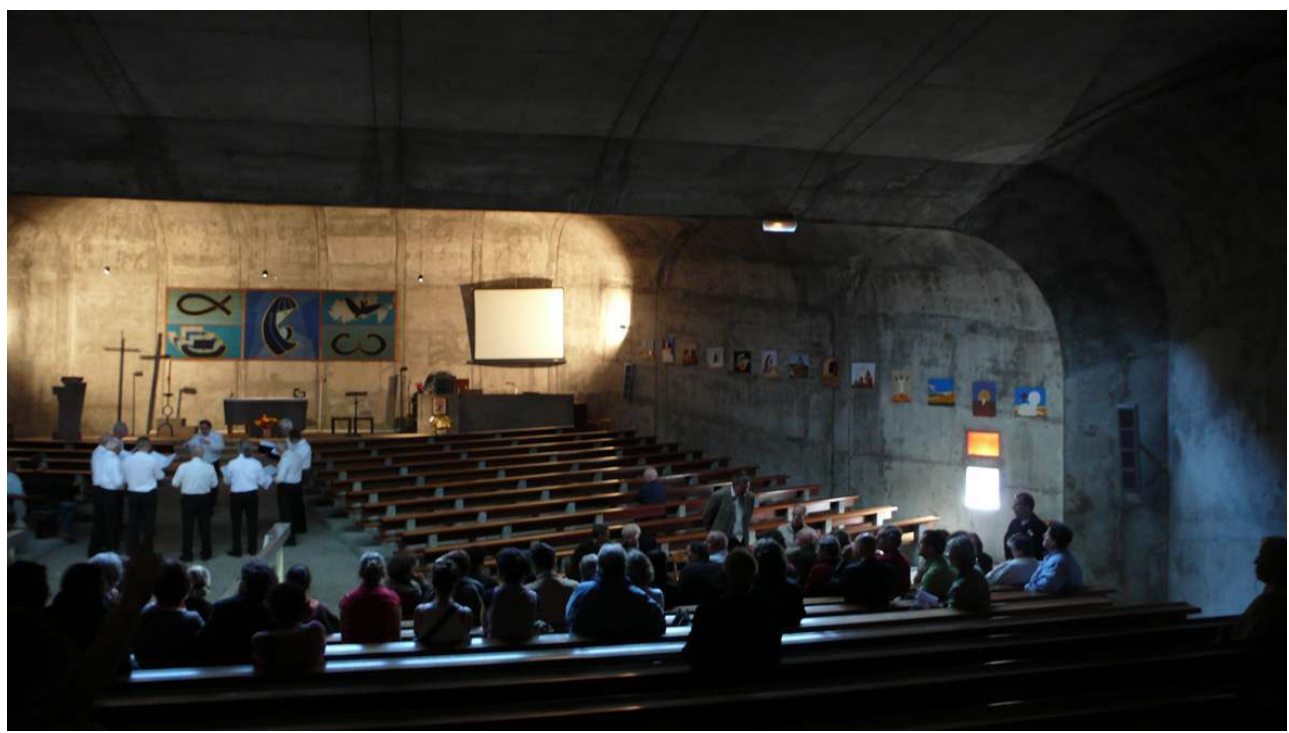

Nef et chœur. Phot. Paul Barnoud.

(c) Atelier Cairn architectes. 
Figure 12

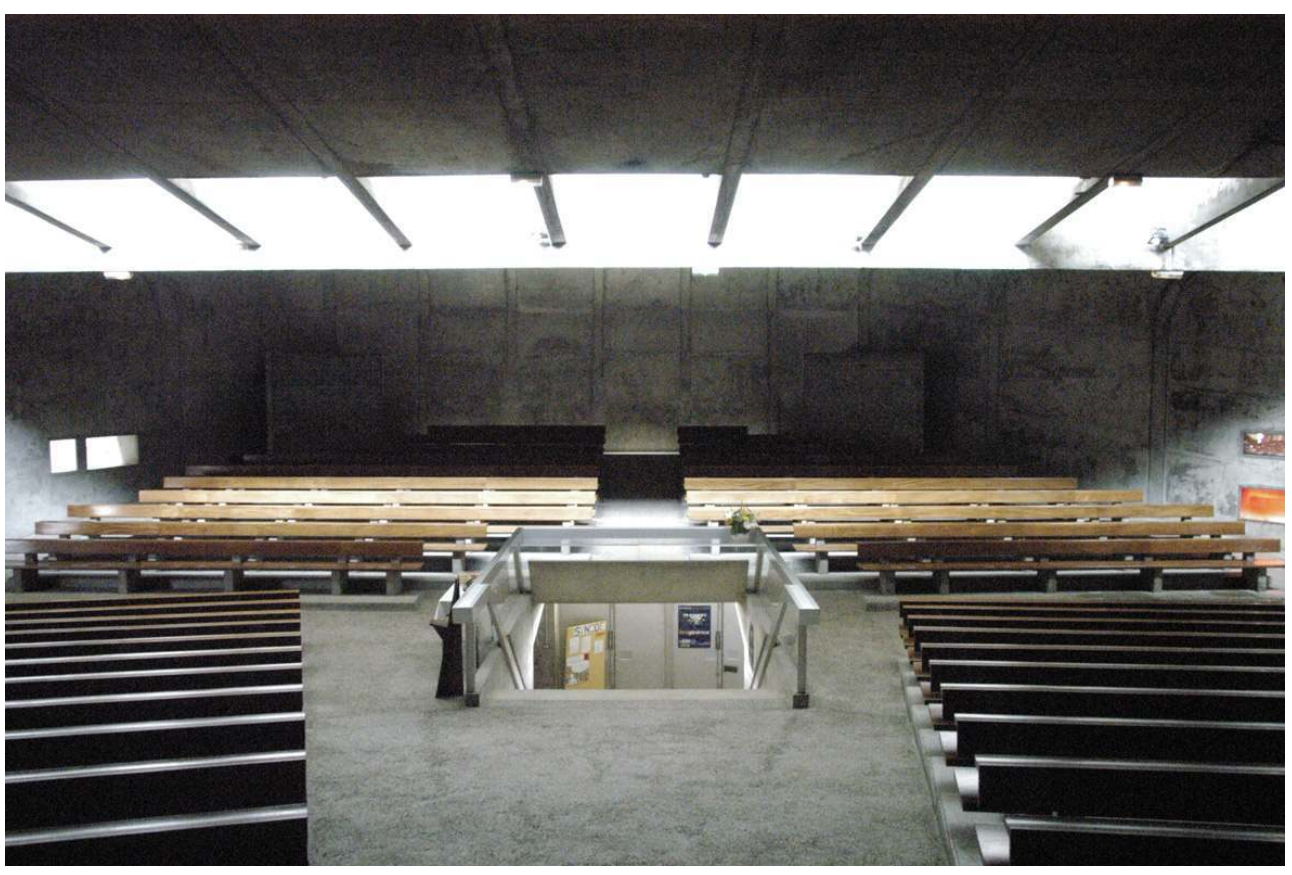

Lanternon central. Phot. Paul Barnoud.

(c) Atelier Cairn architectes.

Figure 13

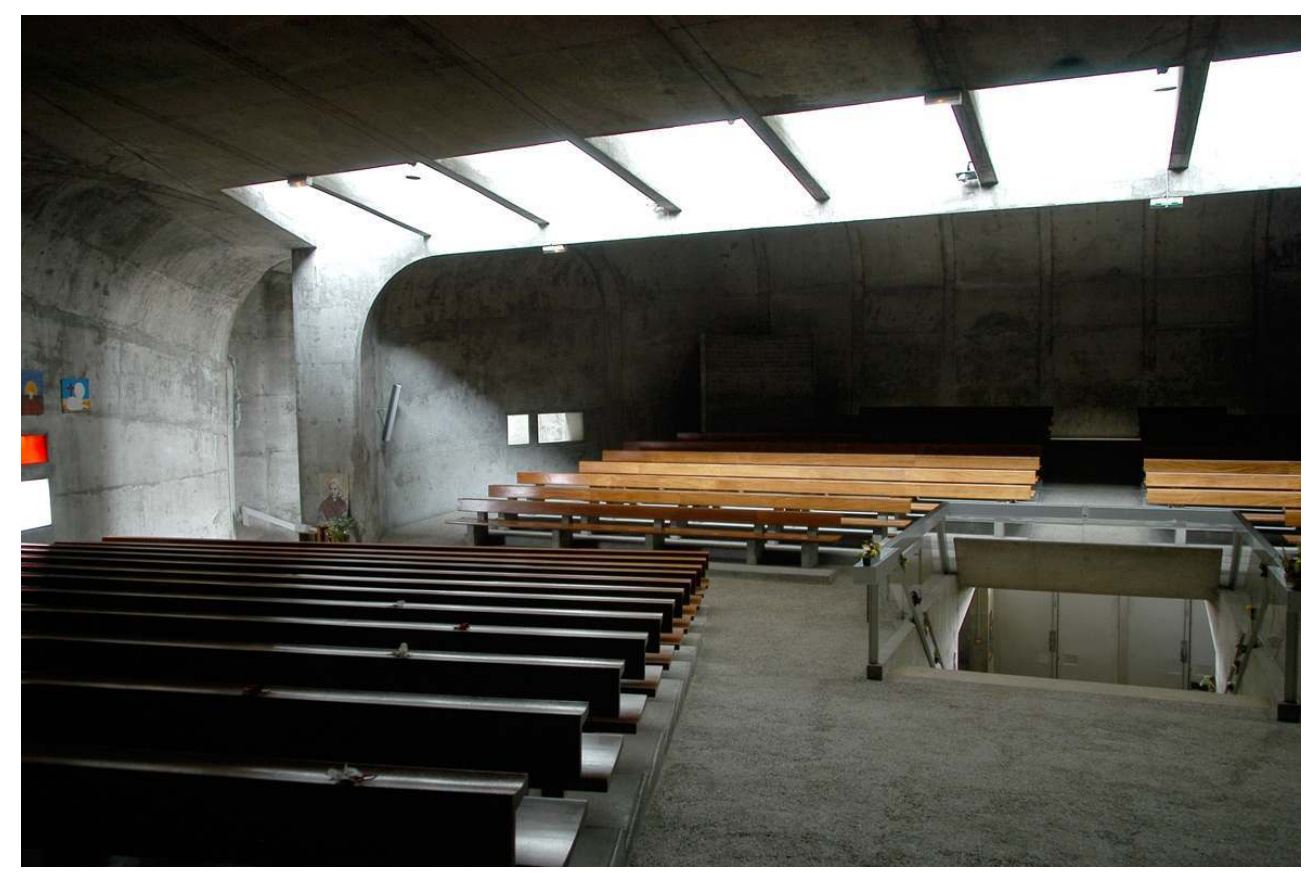

Articulation entre les deux coques. Phot. Paul Barnoud.

(c) Atelier Cairn architectes. 
Figure 14

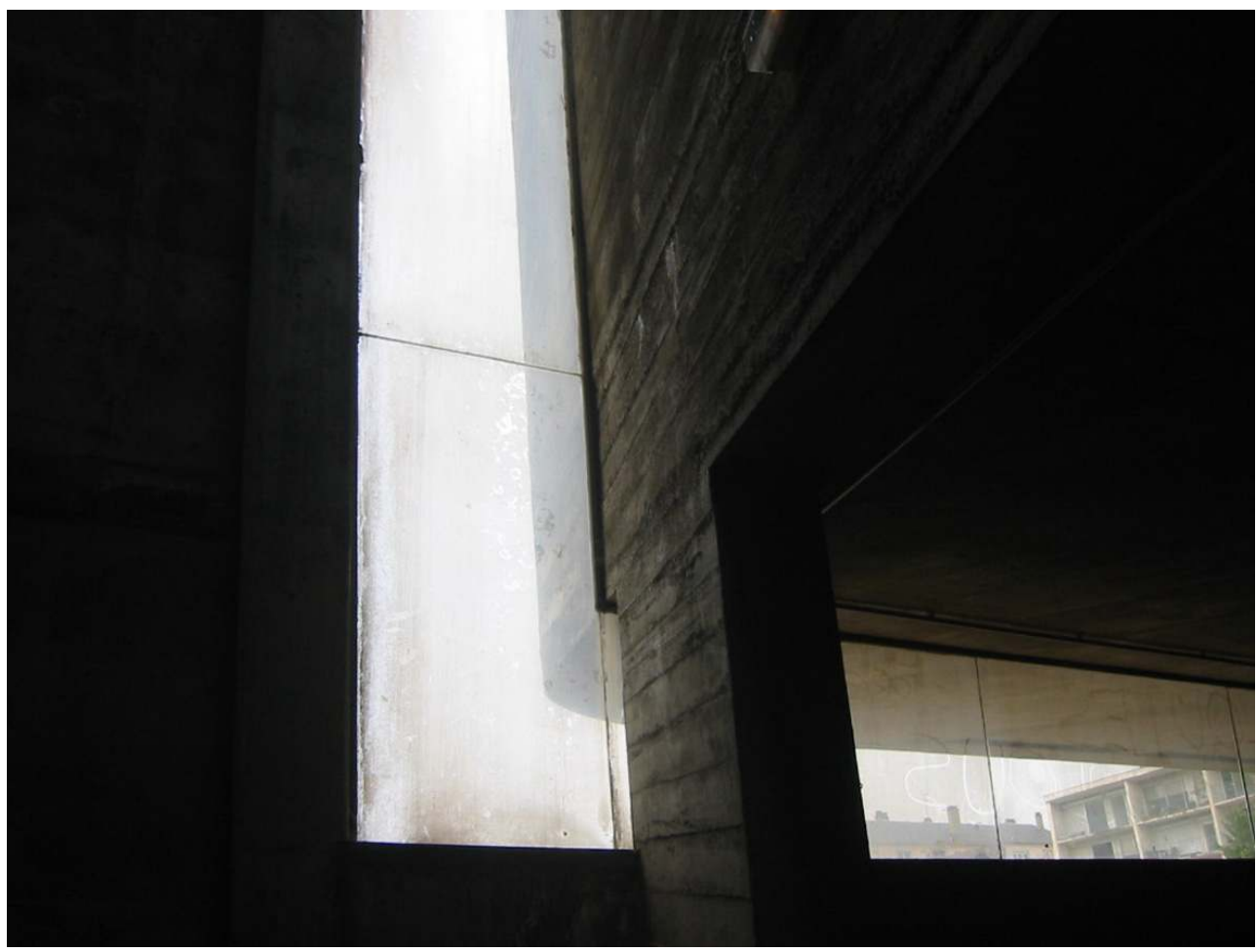

Les points porteurs sont situés en retrait de la façade. Phot. Paul Barnoud.

(c) Atelier Cairn architectes. 
Figure 15

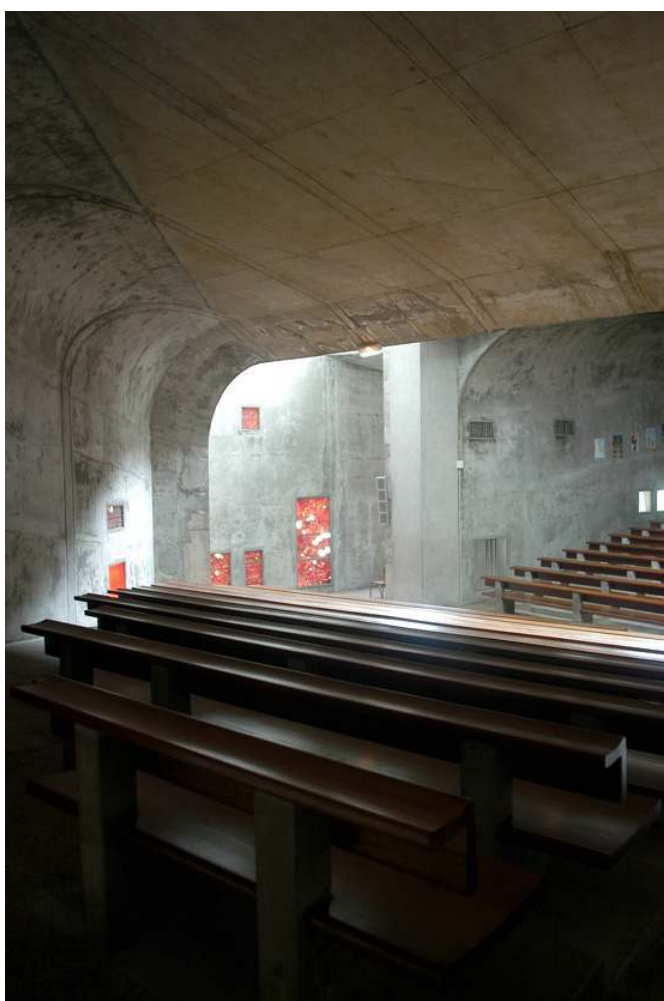

Accès latéral à la nef. Phot. Paul Barnoud.

(c) Atelier Cairn architectes.

\section{Structure et construction}

33 Si l'église apparaît comme l'imbrication de deux coques en béton armé, elle est en réalité construite comme une structure unitaire constituée de poutres longitudinales qui reposent, en extrémité sur les porte-à-faux de la nef et au centre sur le lanternon transversal qui constitue la grande poutre.

Les plafonds rampants des coques de la nef et des confessionnaux convergent vers le centre et le lanternon, animés par le calepinage et le dessin des joints des éléments structurants. (fig. $n^{\circ} 16, n^{\circ} 17, n^{\circ} 18, n^{\circ} 19$ ) 
Figure 16

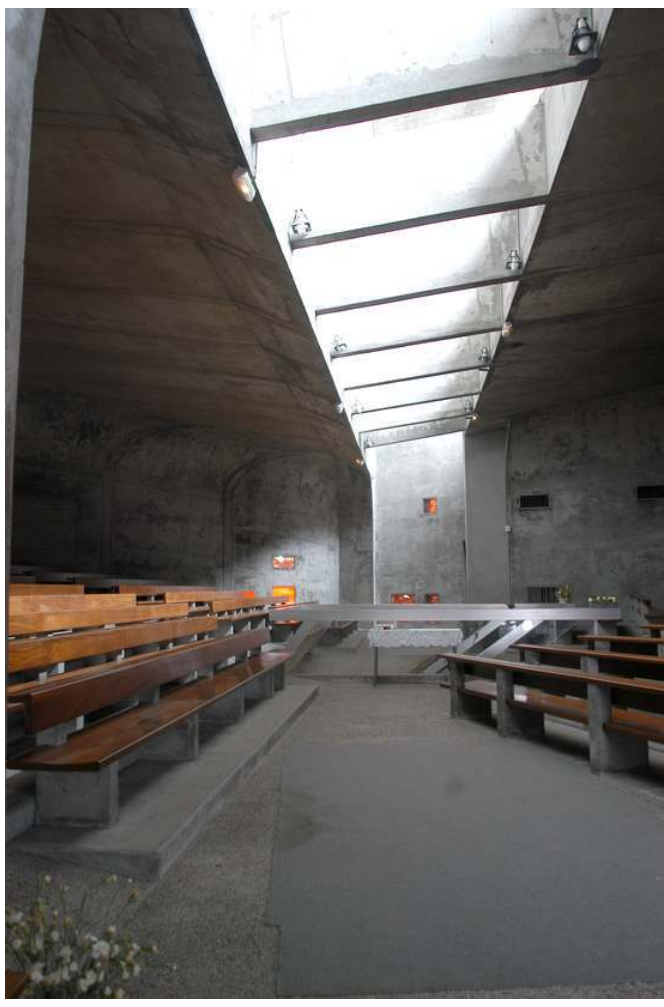

Le lanternon joue le rôle structurel de poutre transversale. Phot. Paul Barnoud. (c) Atelier Cairn architectes. 
Figure 17

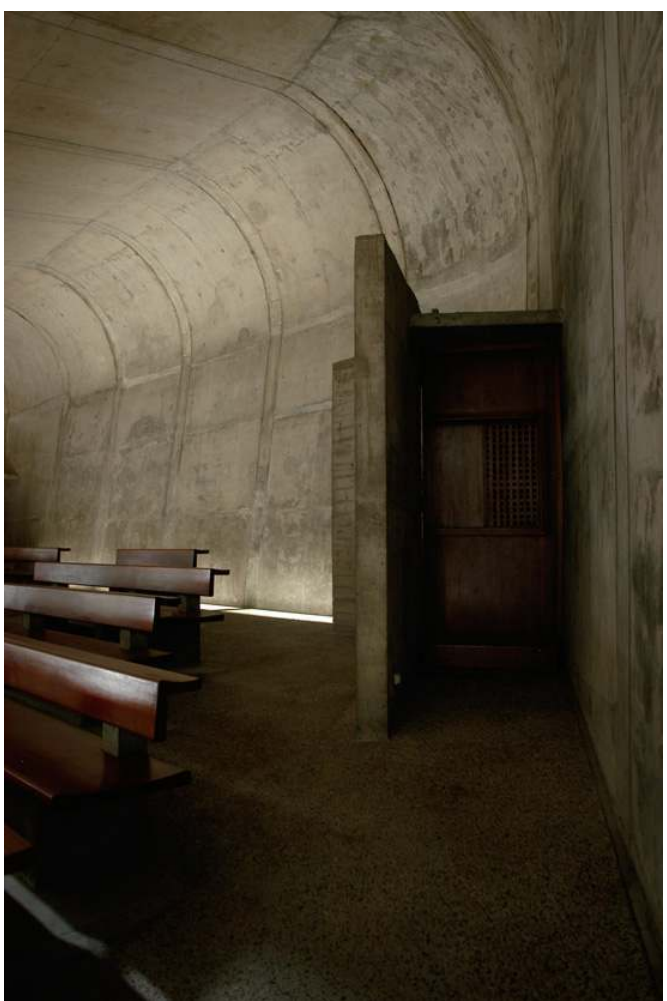

Joints des poutres en béton support de la voûte supérieure. Phot. Paul Barnoud. (c) Atelier Cairn architectes. 
Figure 18

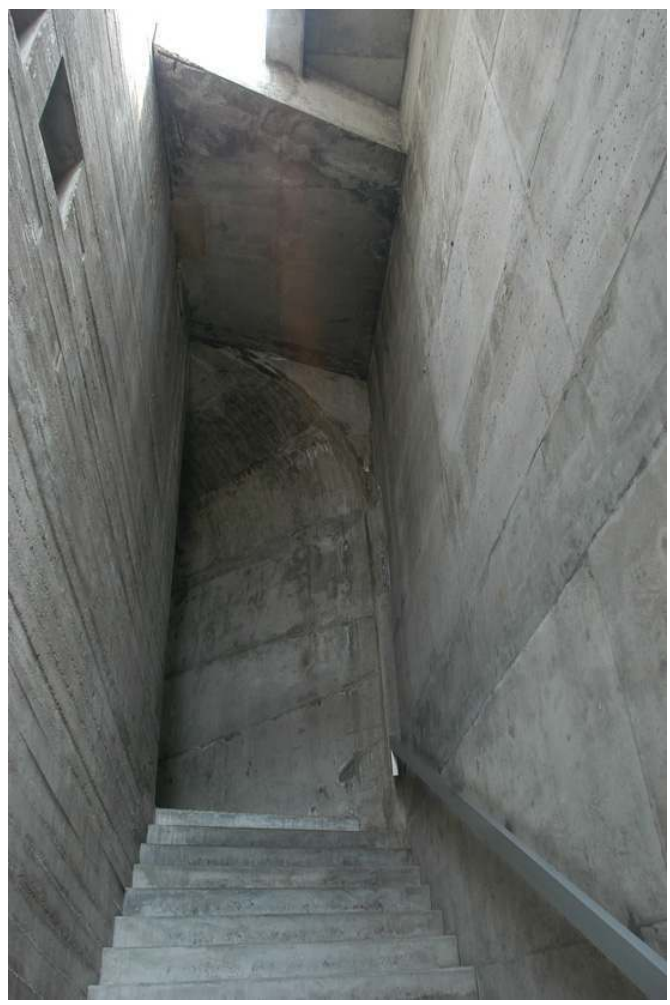

Escalier latéral sud, imbrication des deux coques. Phot. Paul Barnoud. (c) Atelier Cairn architectes. 


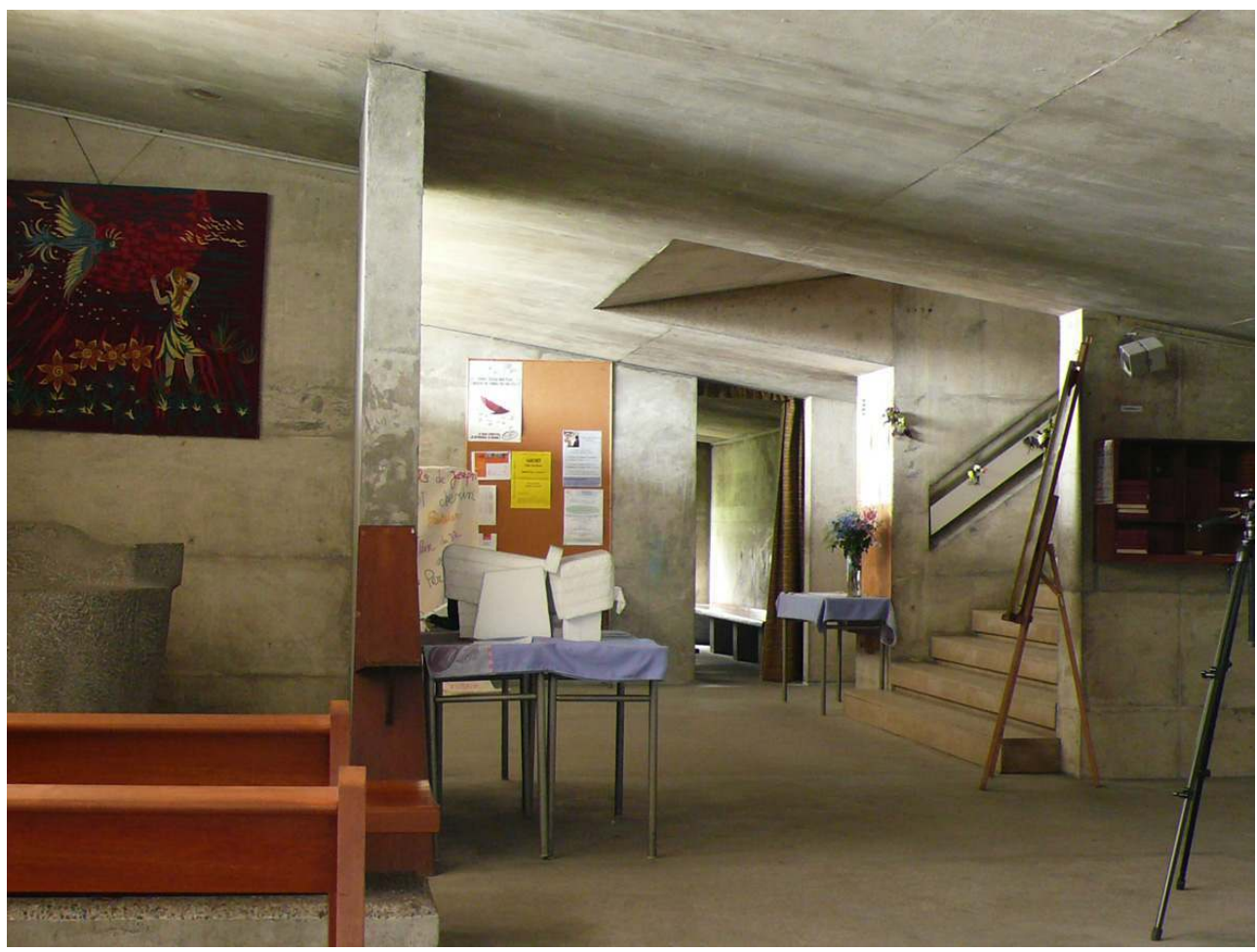

Entrée, fonts baptismaux et chapelle de semaine. Phot. Paul Barnoud.

(c) Atelier Cairn architectes.

\section{Dispositifs du second œuvre et mobilier}

\section{L'éclairage}

L'édifice présente des dispositifs d'éclairage naturel traités soit de façon traditionnelle, par les vitraux et le verre, soit de façon plus contemporaine par l'utilisation de plexiglas. Ainsi :

- la principale source d'éclairage naturel de la nef est un grand lanternon transversal fermé de glaces ;

- de petites ouvertures, fermées de plexiglas, pratiquées dans le sol, à la base des murs de la nef et du chœur, permettent d'éclairer ces derniers par réflexion de la lumière sur le sol extérieur. Pour cette raison le sol des abords de l'église était à l'origine très minéral ; - quelques ouvertures en façade, autrefois fermées par des vitraux, aujourd'hui remplacés en partie par des plexiglas, éclairent la nef au niveau du lanternon ;

- de part et d'autre de la nef, deux grandes failles verticales, équipées en plexiglas, qui se retournent à l'horizontale, permettent d'éclairer naturellement les escaliers latéraux ;

- enfin, la salle de catéchisme est éclairée par une grande paroi de verre, tenue par des montants en aluminium. (fig. $\mathbf{n}^{\circ} 20, \mathbf{n}^{\circ} 21, \mathbf{n}^{\circ} 22, \mathbf{n}^{\circ} 23$ ) 
Figure 20

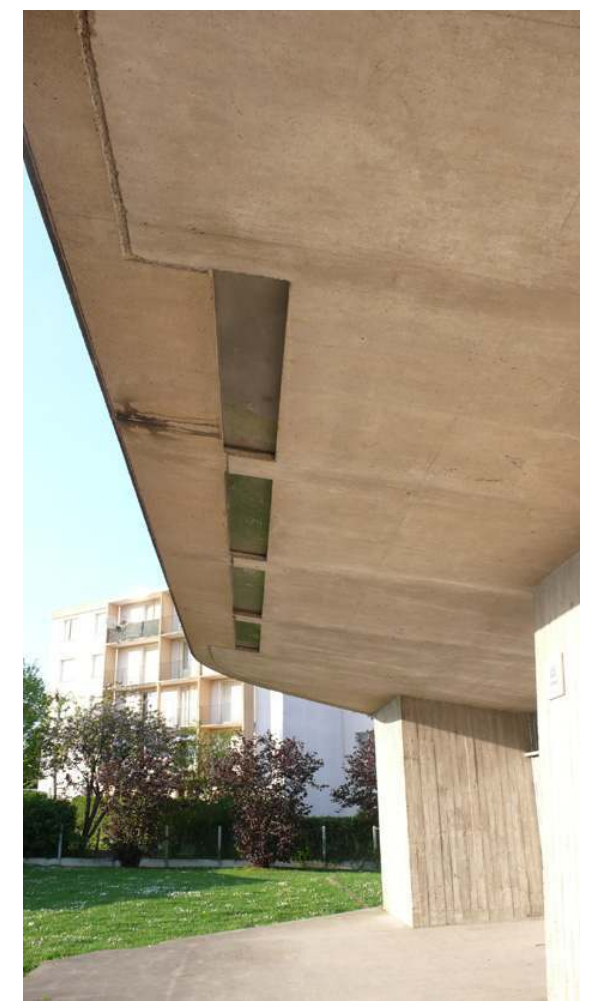

Éclairage par le sol de la salle d'assemblée. Phot. Paul Barnoud. (c) Atelier Cairn architectes.

\section{Figure 21}

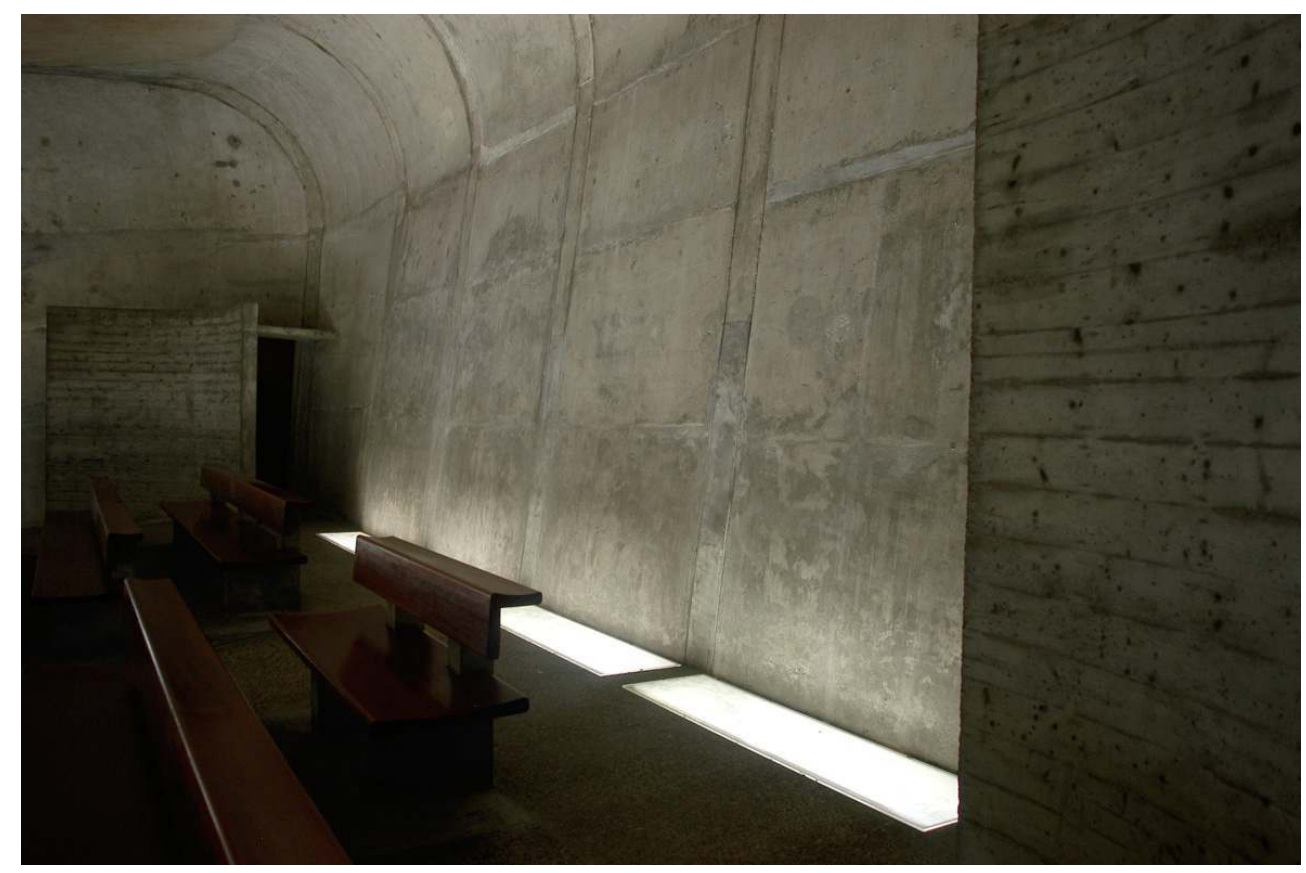

Éclairage indirect du mur ouest. Phot. Paul Barnoud.

(c) Atelier Cairn architectes. 
Figure 22

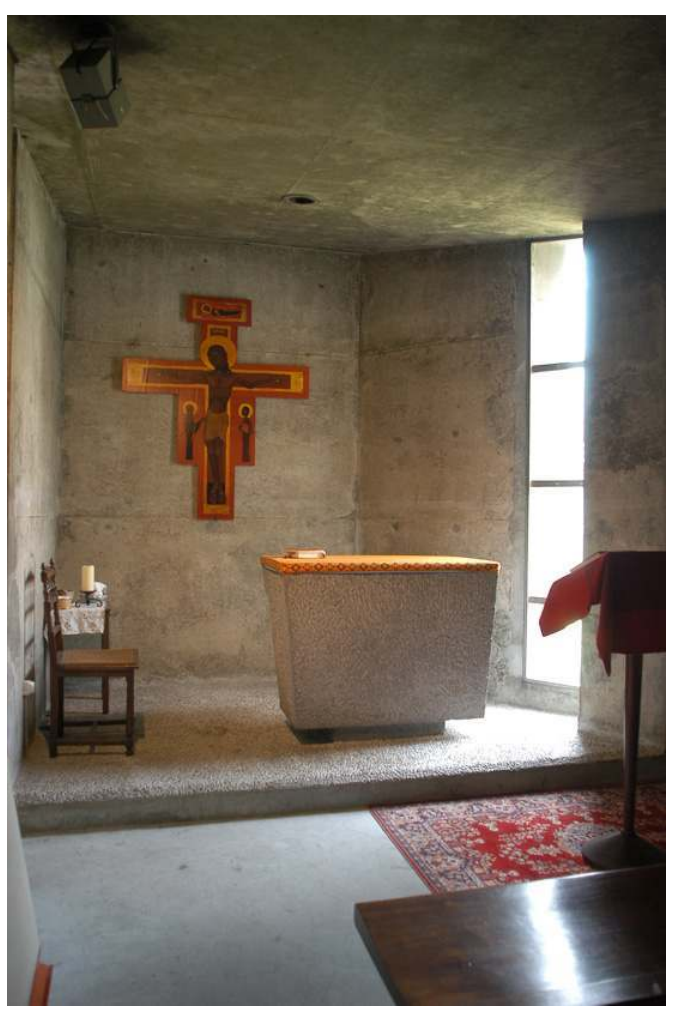

Les fonts baptismaux. Phot. Paul Barnoud. (c) Atelier Cairn architectes. 


\section{Figure 23}

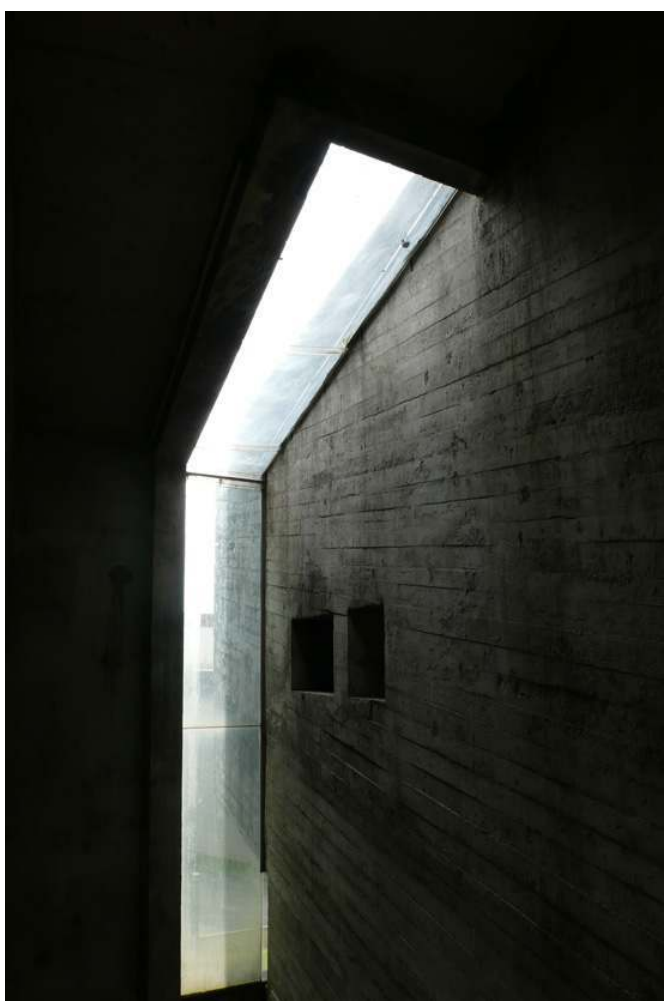

Fente de lumière au droit de l'escalier sud. Phot. Paul Barnoud. (c) Atelier Cairn architectes. 
Figure 24

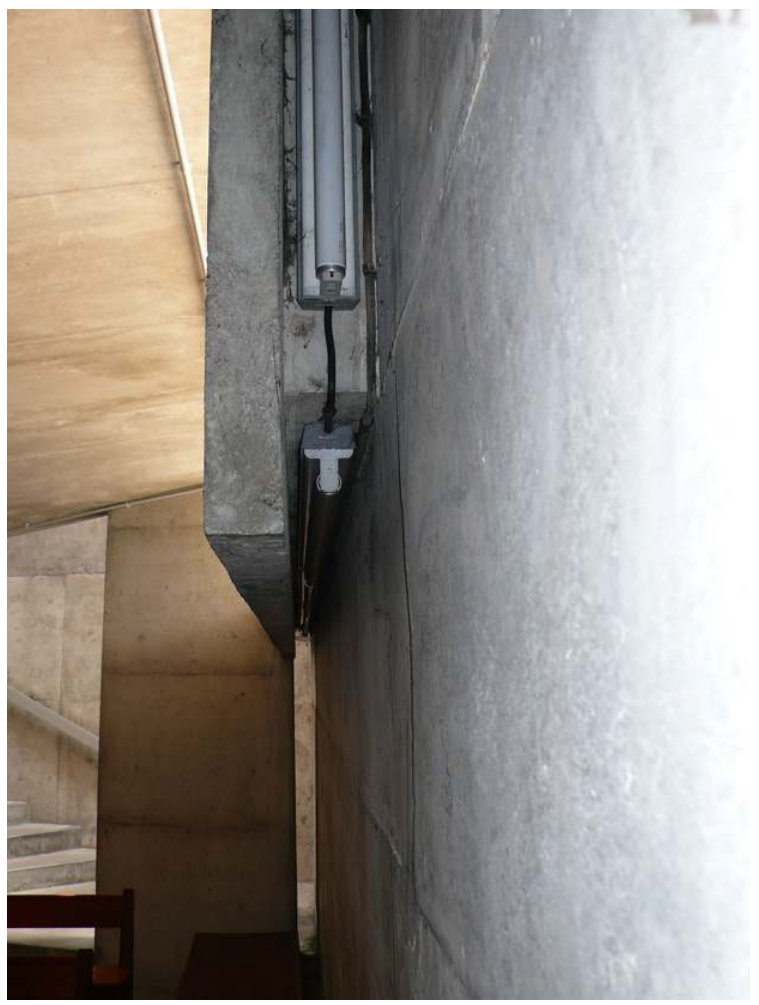

Éclairage électrique indirect. Phot. Paul Barnoud.

(c) Atelier Cairn architectes.

Cette configuration de l'éclairage naturel a servi de base à l'installation de l'éclairage artificiel. Des spots ont été placés dans les ouvertures, au sol, côté chœur, et entre les confessionnaux. Trois suspentes viennent éclairer l'ambon, l'autel et le tabernacle. D’autres spots ont été accrochés le long de la poutre du lanternon. Des néons ont été encastrés dans les cadres béton des fentes de lumière. Enfin les équipements électriques ont été encastrés dans le sol du chœur. (fig. $\mathbf{n}^{\circ} \mathbf{2 4}$ )

37 Les vitraux

38 Ils occupent quelques baies de la nef, à proximité des escaliers, essentiellement au nord. Conçus et réalisé par Odette Ducarre, ils sont exécutés en technique traditionnelle selon un dessin abstrait de lignes courbes. Les couleurs dominantes sont des rouges. (fig. $n^{\circ} 25$ ) 


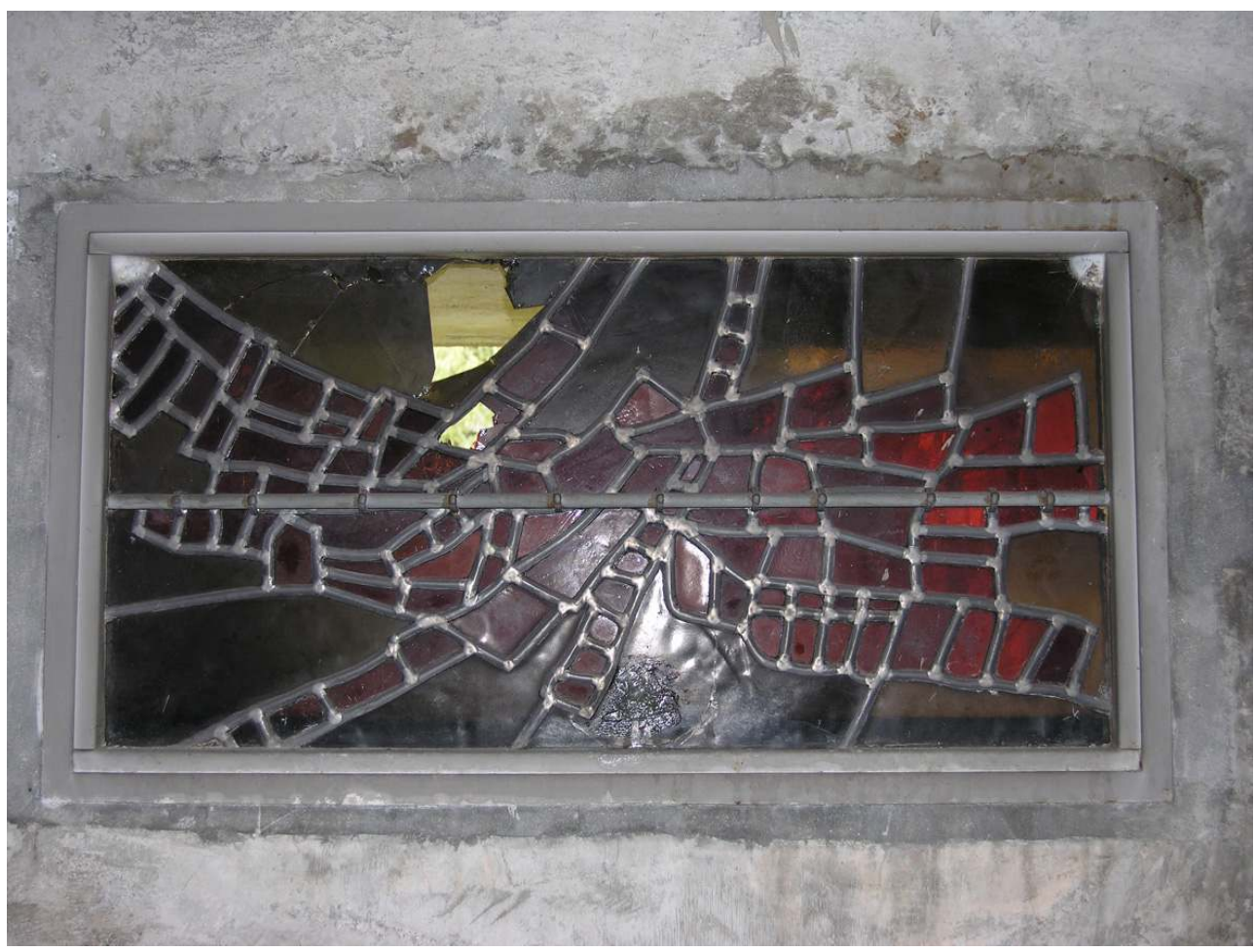

Un des vitraux conservés. Phot. Paul Barnoud.

(c) Atelier Cairn architectes.

\section{Les sols}

Les sols ont dans l'ensemble été traités de façon assez brute : béton de gravillons lavés pour la nef, béton brut pour les espaces du rez-de-chaussée et les escaliers latéraux. Seul l'escalier principal est en pierre. (fig. $\mathbf{n}^{\circ} \mathbf{2 6}$ ) 


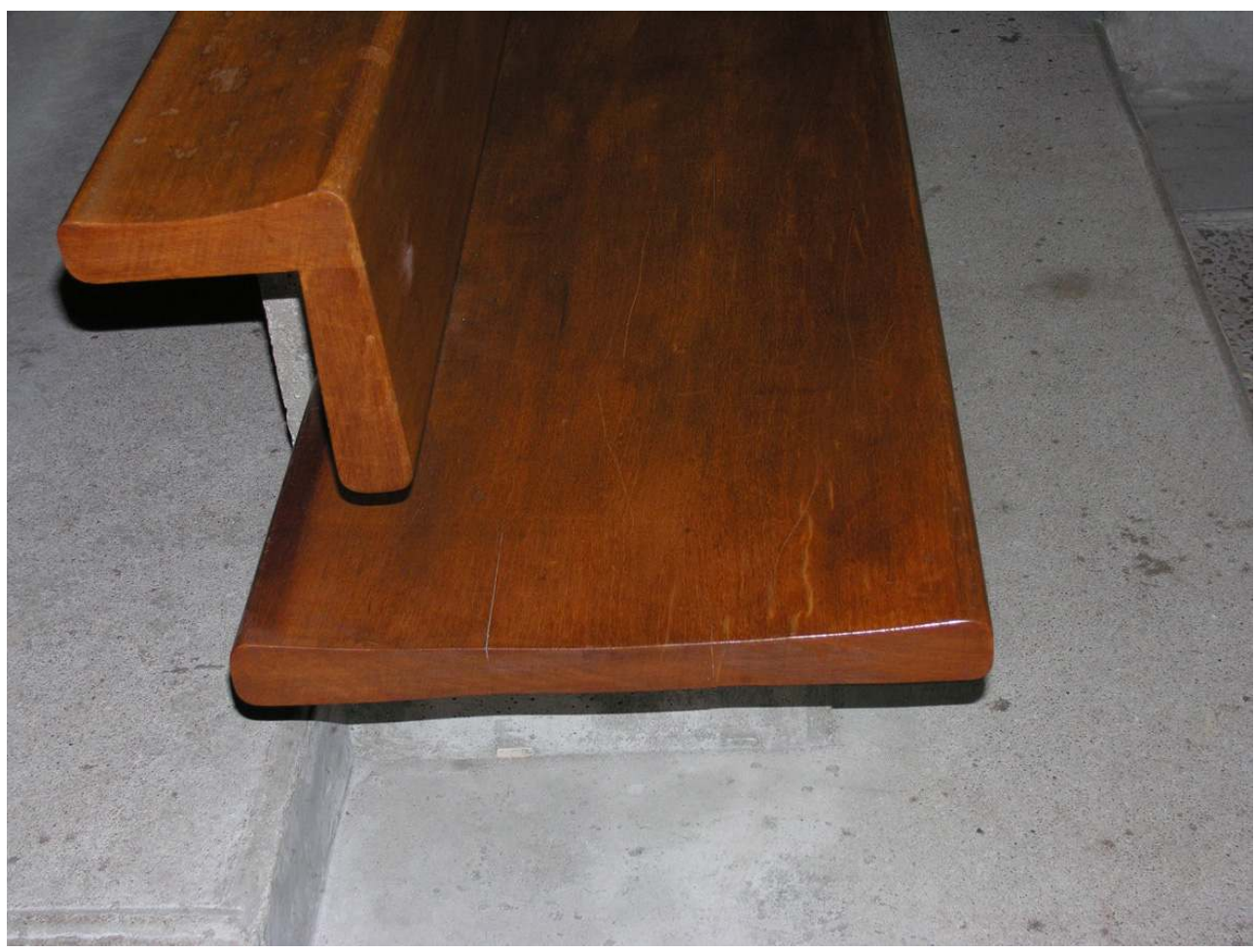

Sol en gravillons lavés et mobilier intégré à l'architecture. Les bancs reposent sur des socles en béton. Phot. Paul Barnoud.

(c) Atelier Cairn architectes.

\section{Le mobilier}

40 Réalisé par Lipsi, le mobilier est constitué de l'ambon, du tabernacle, des fonts baptismaux et de l'autel. L'ambon, l'autel et les fonts baptismaux ont été taillés dans un bloc de pierre volcanique d'Auvergne. D'aspect monolithique, ces sculptures dépouillées reprennent l'esthétique primaire de l'édifice et répondent aux directives issues du concile de Vatican II.

41 Creusés dans la même pierre dure, les fonts baptismaux présentent le même aspect de matière à l'état brut. Ses courbes évoquent l'écoulement de l'eau.

Plus travaillé, le tabernacle, en granite de Haute-Savoie, conserve pourtant l'aspect monolithique de l'ensemble du mobilier. Il renferme deux ciboires gigognes contemporains, en bronze bruni et doré, réalisé par un artisan nivernais, M. Ducarre.

Le mobilier de Sainte-Bernadette est particulièrement bien adapté à l'édifice. Il reprend l'idée de suspension de masse, de rugosité pour mieux célébrer la libération de la pesanteur. (fig. $\mathbf{n}^{\circ} 27, \mathbf{n}^{\circ} 28, \mathbf{n}^{\circ} 29, \mathbf{n}^{\circ} 30$ ) 
Figure 27

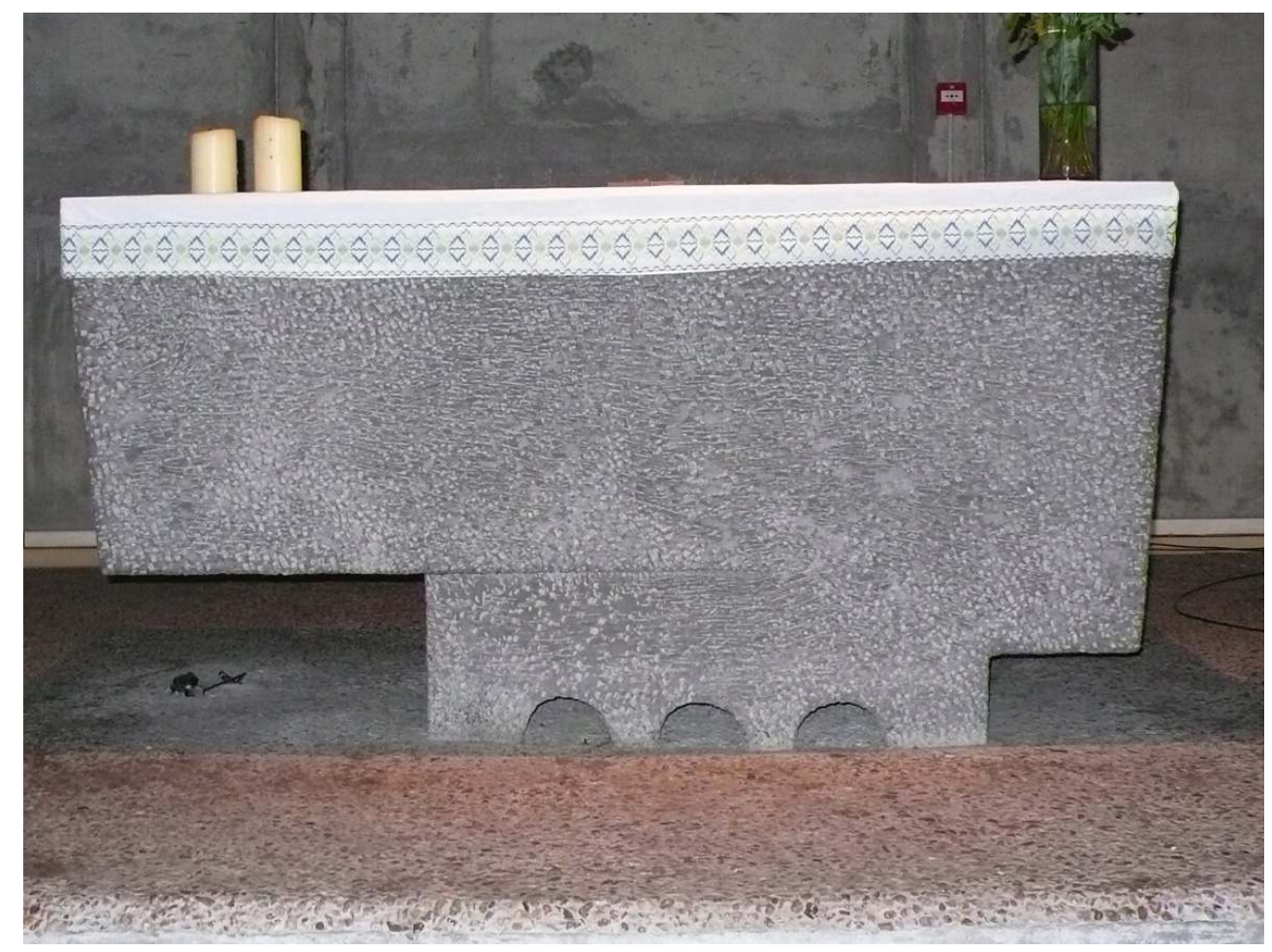

L'autel. Phot. Paul Barnoud.

(c) Atelier Cairn architectes.

Figure 28

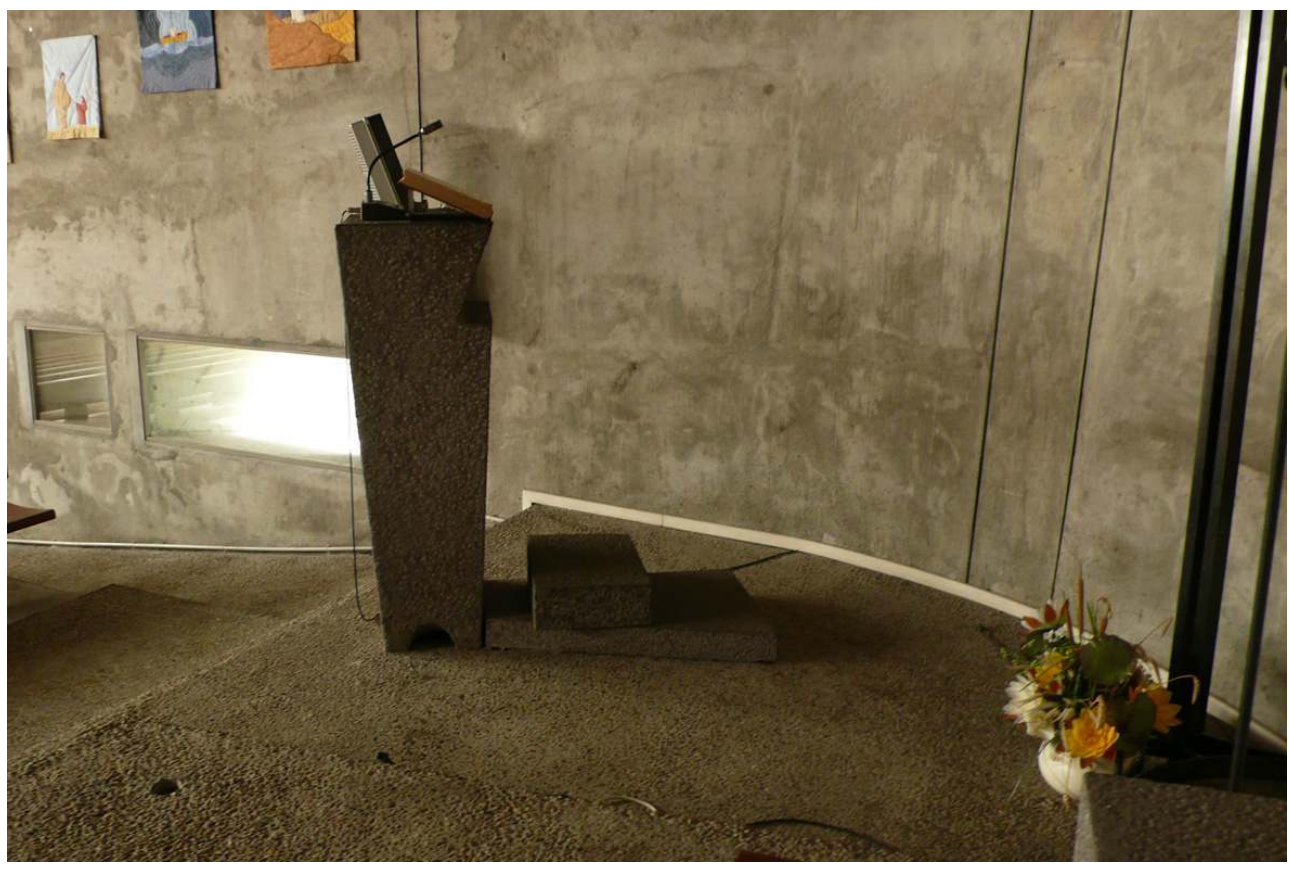

L'ambon. Phot. Paul Barnoud.

(c) Atelier Cairn architectes. 


\section{Figure 29}

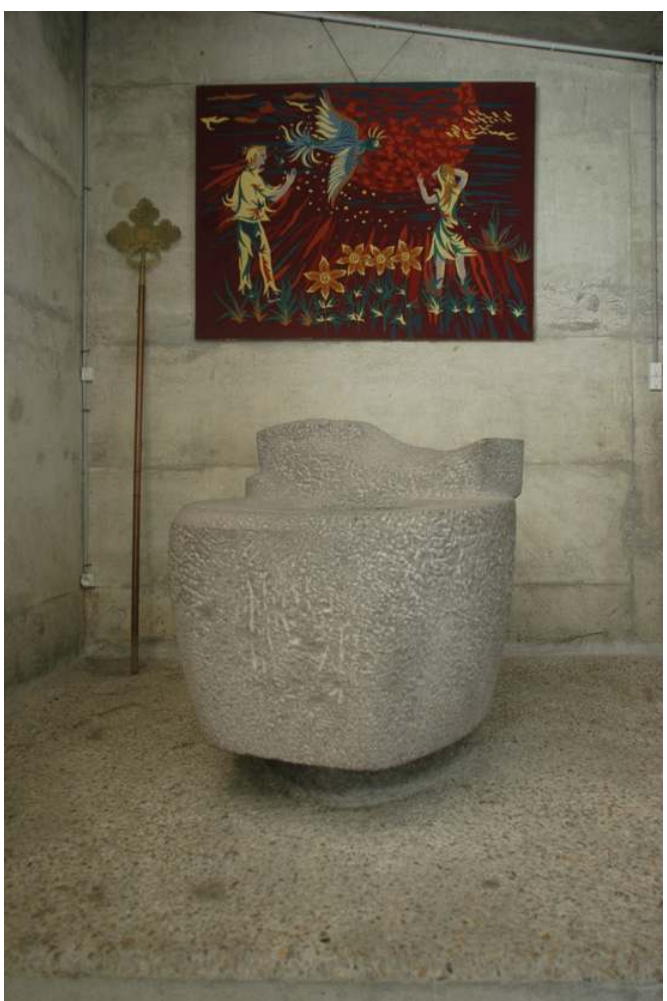

Cuve baptismale. Phot. Paul Barnoud.

(c) Atelier Cairn architectes. 
Figure 30

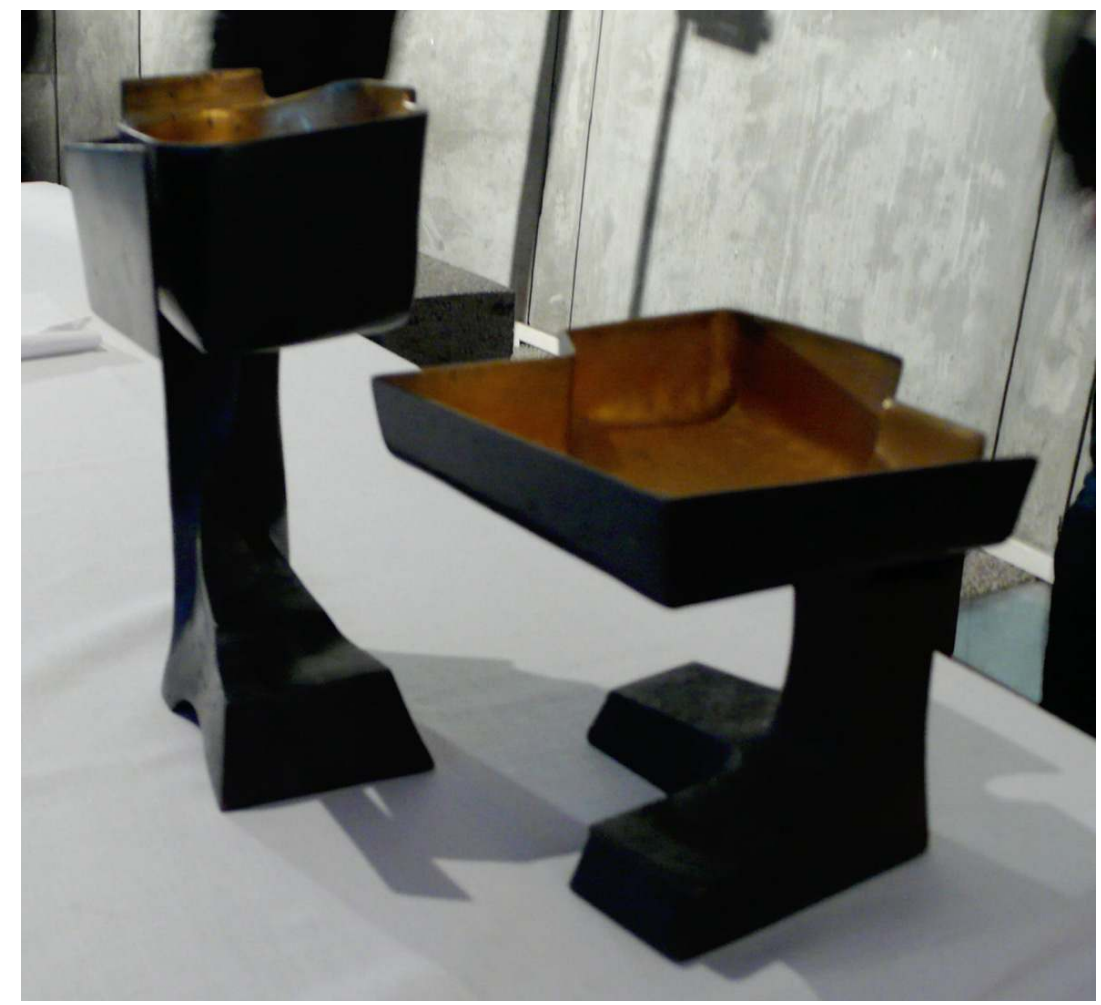

Calice et ciboire. Phot. Paul Barnoud.

(c) Atelier Cairn architectes.

\section{Les abords}

Les abords présentent un grand axe d'entrée, que soulignent des éclairages encastrés dans de petits plots de béton, imbriqués dans les bordures de trottoir. L'édifice, aujourd'hui bordé de verdure, devait à l'origine être entouré de cailloux de ballast. Mais seul le glacis entre les deux niveaux de sol extérieur est encore recouvert de ces cailloux, ces derniers ayant été scellés dans le béton. (fig. $n^{\circ} 31, n^{\circ} 32, n^{\circ} 33, n^{\circ} 34$ ) 
Figure 31

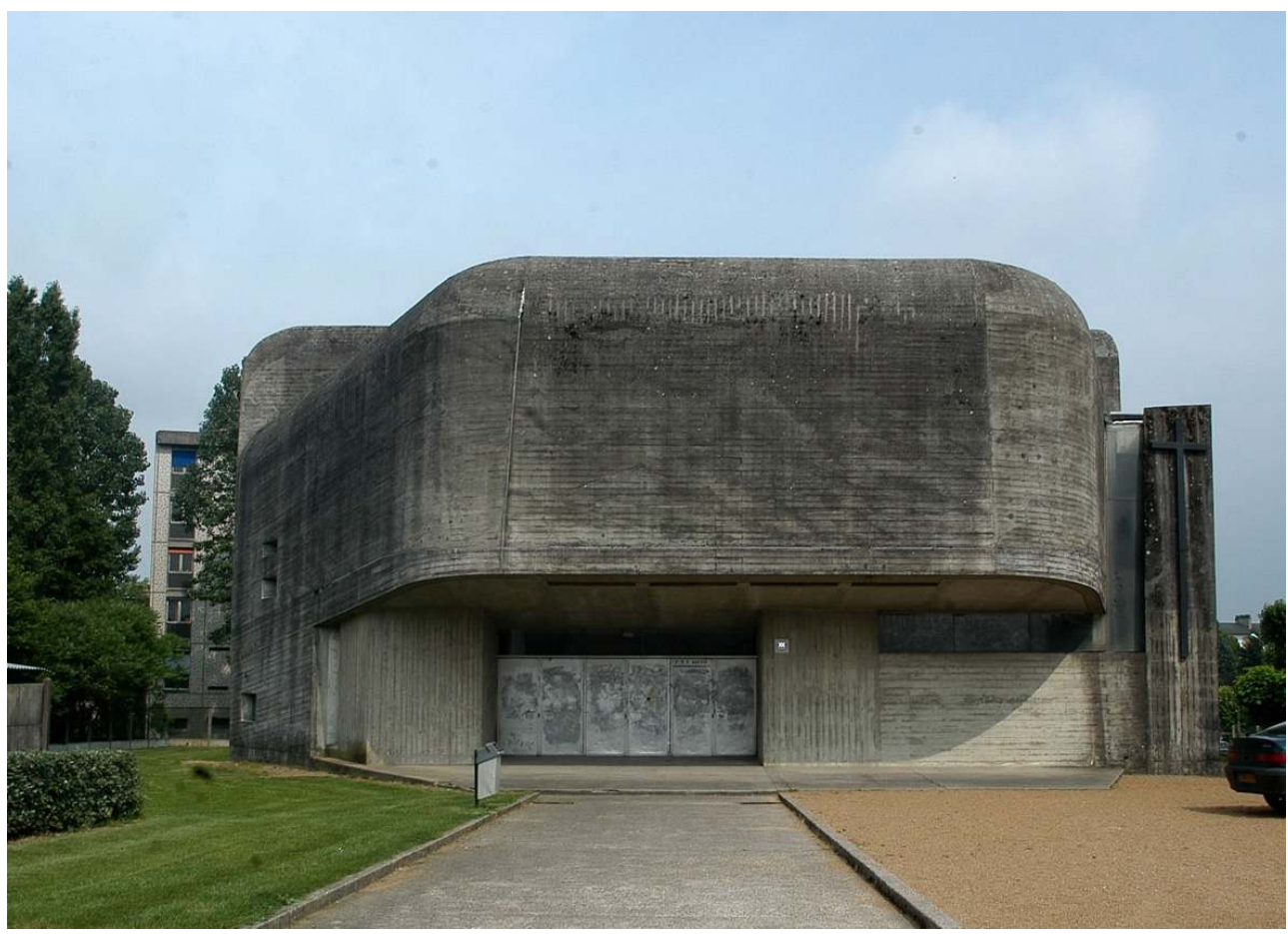

Façade ouest. Phot. Paul Barnoud.

(c) Atelier Cairn architectes.

\section{Figure 32}

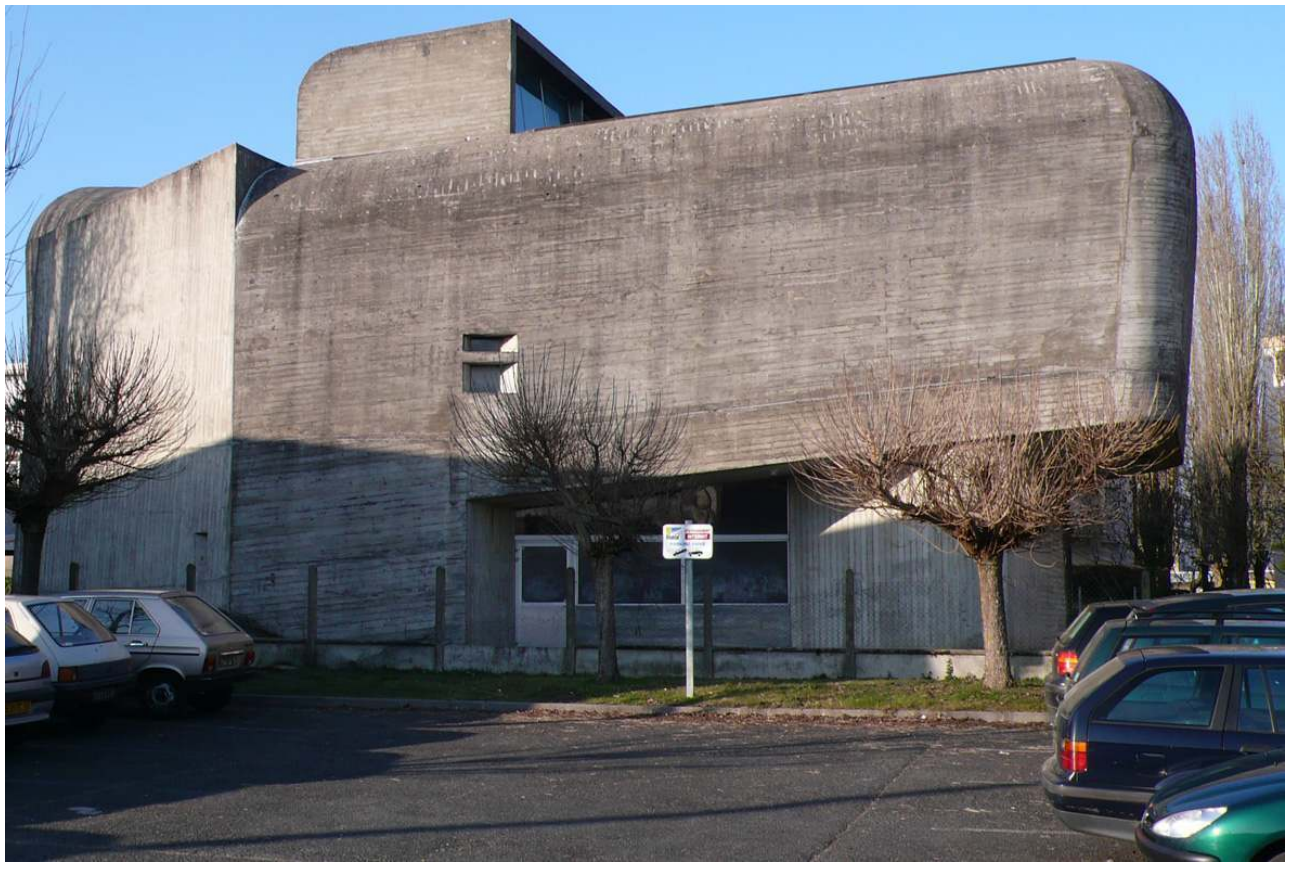

Façade sud. Phot. Paul Barnoud.

(c) Atelier Cairn architectes. 
Figure 33

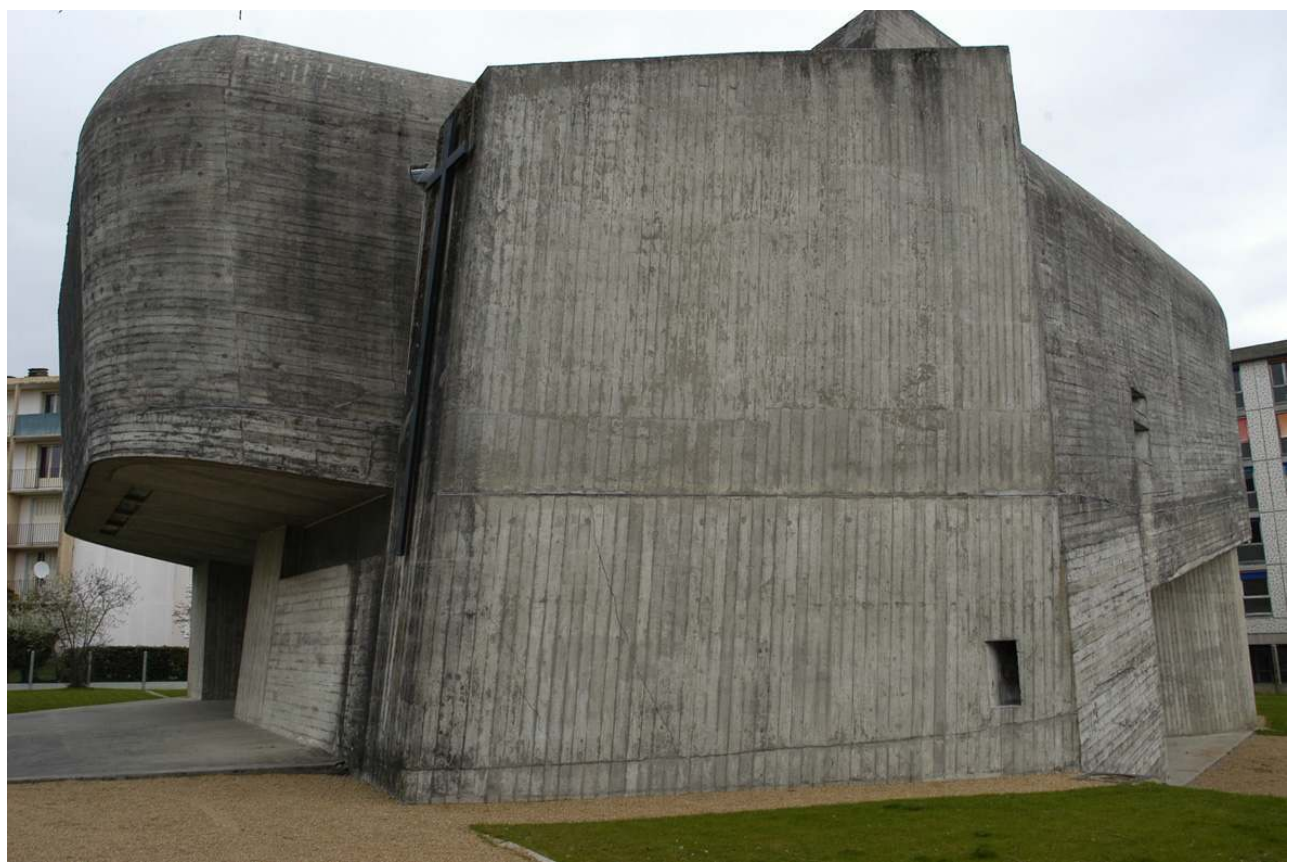

Façade sud. Phot. Paul Barnoud.

(c) Atelier Cairn architectes.

\section{Figure 34}

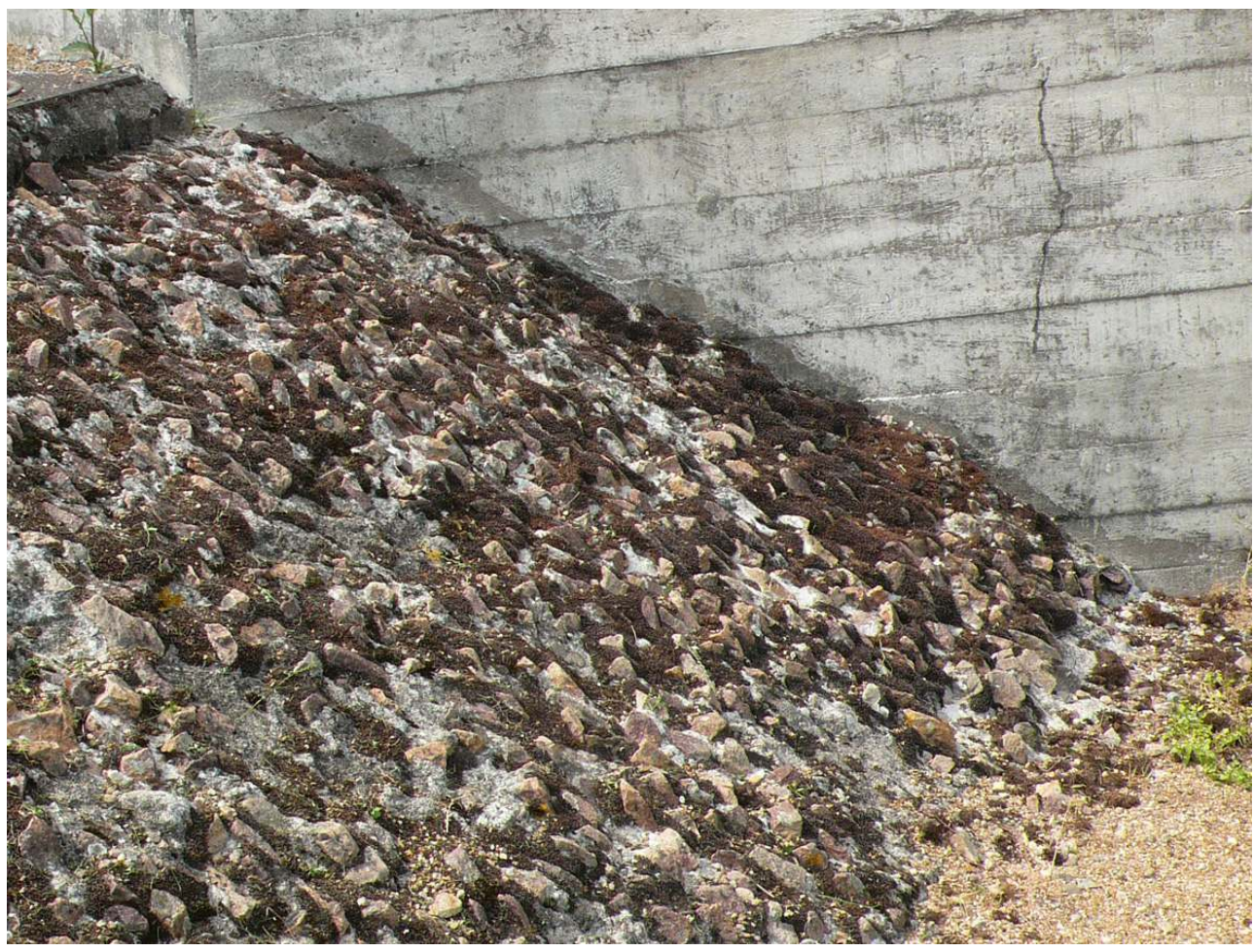

Glacis recouvert de cailloux de ballast. Phot. Paul Barnoud.

(c) Atelier Cairn architectes. 


\section{Édifice précurseur et témoin}

sustentation au-dessus du sol. Les architectes développent une des caractéristiques des bunkers, les porte-à-faux; ils vont cependant s'éloigner de leurs modèles pour les percements. Alors que les fentes horizontales sont de règle dans la fortification moderne, Claude Parent et Paul Virilio choisissent de privilégier les percements verticaux qui deviennent des lignes de fracture entre deux coques légèrement décalées. Le schéma en plan de cet emboîtement ou de ce télescopage de coques servira de logo au groupe Architecture Principe tout au long des neuf numéros de la revue qu'il publie. Il y a quelque chose de dynamique dans cette imbrication, l'idée d'un mouvement entre des formes autonomes qui se combinent et se soutiennent mutuellement.

L'utilisation de l'hexagone pour le plan est singulière. C'est une forme extrêmement rare pour une église. Claude Parent s'intéressait aux plans sur trames hexagonales de Frank Lloyd Wright, il appréciait l'ouverture de l'espace générée par l'angle à $120^{\circ}$. Les architectes ont composé leur projet à partir de l'hexagone du plan et de la structure axée des coques, ils retrouvaient ainsi la tension entre espace centré et espace axé qui parcourt l'architecture des églises depuis l'Antiquité.

La méthode de travail des deux concepteurs est d'une grande modernité. L'édifice est conçu en coupes à partir de croquis très rapides. Cette démarche s'inscrit en opposition avec la tradition française de composition à partir d'un plan directeur. Ce n'est pas à partir du plan que le projet s'ordonne, mais à partir de la coupe, dans le rapport à l'étage, à l'oblique, à la pente. Par la suite, la conception passe par la réalisation de maquettes et c'est en retravaillant à partir de la première que Claude Parent aboutira au projet définitif dont les dimensions ont été réduites. Ce mode de conception rapproche Claude Parent et Paul Virilio de nombre d'architectes contemporains qui utilisent les maquettes pour découvrir des volumétries complexes.

Les architectes de Sainte-Bernadette s'exonèrent, non seulement de la primauté du plan, mais aussi de la démarche structurelle. Leur projet n'est pas pensé au départ en fonction d'une structure. Celle-ci sera conçue dans un second temps par un ingénieur. Cette liberté qu'ils se donnent leur permet de découvrir de nouvelles formes. Leur projet résistera bien aux quelques modifications induites par les contraintes structurelles; c'est ainsi que le lanternon, au départ limité au tiers de la largeur de la nef, est étendu à toute la largeur pour assurer le rôle structurel d'une poutre transversale soutenant les poutres rampantes longitudinales. Selon Paul Virilio, cette transformation, loin d'amoindrir la force du parti, l'a, au contraire, renforcée.

50 Le concept architectural de Sainte-Bernadette est fondé sur la correspondance entre l'intérieur et l'extérieur. Là où l'on attendrait une masse considérable de béton comme 
dans les authentiques bunkers, nous trouvons une double coque très mince, entièrement habitée; le volume intérieur correspond en tous points au volume extérieur. La lumière elle-même illustre cette correspondance en venant souligner, par réflexion, la courbe de la voûte supérieure. Paul Virilio avait théorisé l'idée d'un bâtiment dont l'espace intérieur correspondrait complètement à l'extérieur, un édifice dont la structure n'occulterait pas la forme: "l'influence de l'enveloppe extérieure, son rôle protecteur, ont totalement occulté l'effet de capacité, en mettant en valeur les fonctions purement techniques (porteur, soutènement), ce qui fait que pour l'essentiel, l'architecture ne nous a guère montré jusqu'ici que «l'échafaudage » de son contenu...[...] L'utilisation en continuité de toutes les surfaces, l'émancipation du plancher au détriment des autres éléments architectoniques, vont pousser au dehors, en quelque sorte, ce « noyau positif du volume contenu, et de ce fait abolir au niveau de la logique formelle, le vieil antagonisme architectural entre intérieur et extérieur, celui-ci ne subsistant plus qu'au niveau de l'usage $»^{19}$. Le béton armé a permis aux architectes de s'affranchir d'une réflexion constructive, comme élément fondateur du projet, au profit d'une démarche spatiale et plastique.

51 Cette œuvre, réalisée à deux voix, a résisté aux économies imposées par le maître d'ouvrage et aux avatars de la réalisation. Bien que d'un aspect peu conventionnel, le projet a répondu à toutes les exigences du maitre d'ouvrage, qui a trouvé dans son usage une pleine satisfaction. Soulignons le fait que cette église a été choisie par ses utilisateurs pour eux-mêmes, sans qu'aucune autorité architecturale ne se soit exprimée sur la qualité artistique de l'œuvre.

52 Aujourd'hui, Sainte-Bernadette n'a rien perdu de sa force subversive comme en témoignent des commentaires récurrents remettant en cause l'honnêteté des concepteurs :

53 « On nous fera difficilement voir dans ce bunker du mur de l'Atlantique le visage ouvert de l'église d'aujourd'hui et l'expressions des béatitudes évangéliques...Dans cette œuvre les architectes nous imposent abusivement le fruit de théories personnelles et très contestables. $»^{20}$

54 «C'est un moment dans la construction d'une œuvre personnelle qui se contemple ellemême; mais le rapport avec le lieu de culte, maison de Dieu et d'une communauté vivante? $»^{21}$

On ne peut être qu'étonné de l'absence de clairvoyance des critiques. En effet, si certains n'apprécient pas les formes de Sainte-Bernadette, ils ne peuvent lui dénier le fait qu'elle ait été construite pour et par une communauté vivante qui, pendant toute la période où l'édifice était un centre pastoral très actif, investi par un ou deux prêtres, a pleinement rempli son programme de lieu de culte et de maison communautaire. La pratique précède ici la reconnaissance officielle qui ne viendra que bien plus tard et qui ne s'est pas encore transcrite par des mesures concrètes vis-à-vis de cet édifice exceptionnel. Il annonce, avec trente ans d'avance, les recherches sur la déconstruction, sur l'assemblage aléatoire des volumes et sur les formes libérées de l'orthogonalité. (fig. $n^{\circ} 35, n^{\circ} 36$ ) 


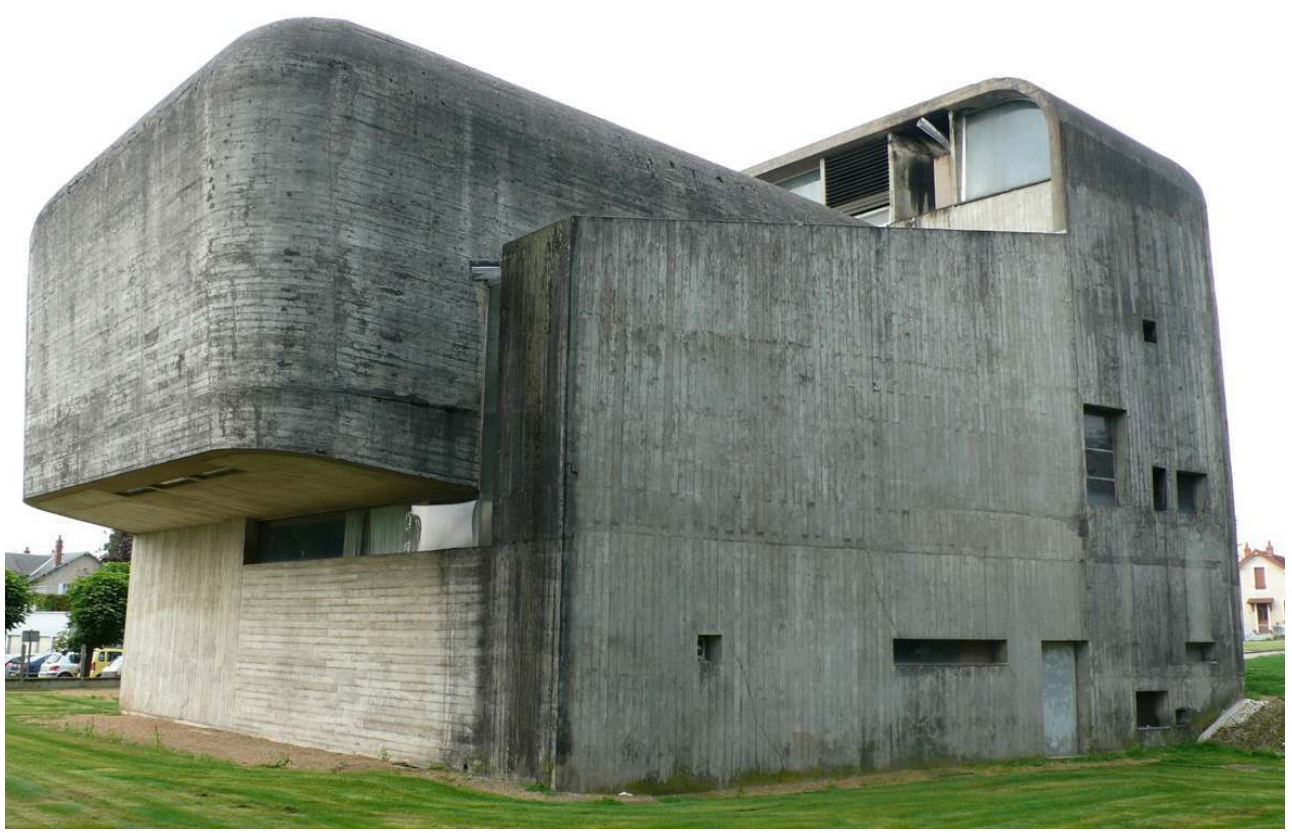

Le chœur surélevé, façades nord et est. Phot. Paul Barnoud.

(c) Atelier Cairn architectes.

Figure 36

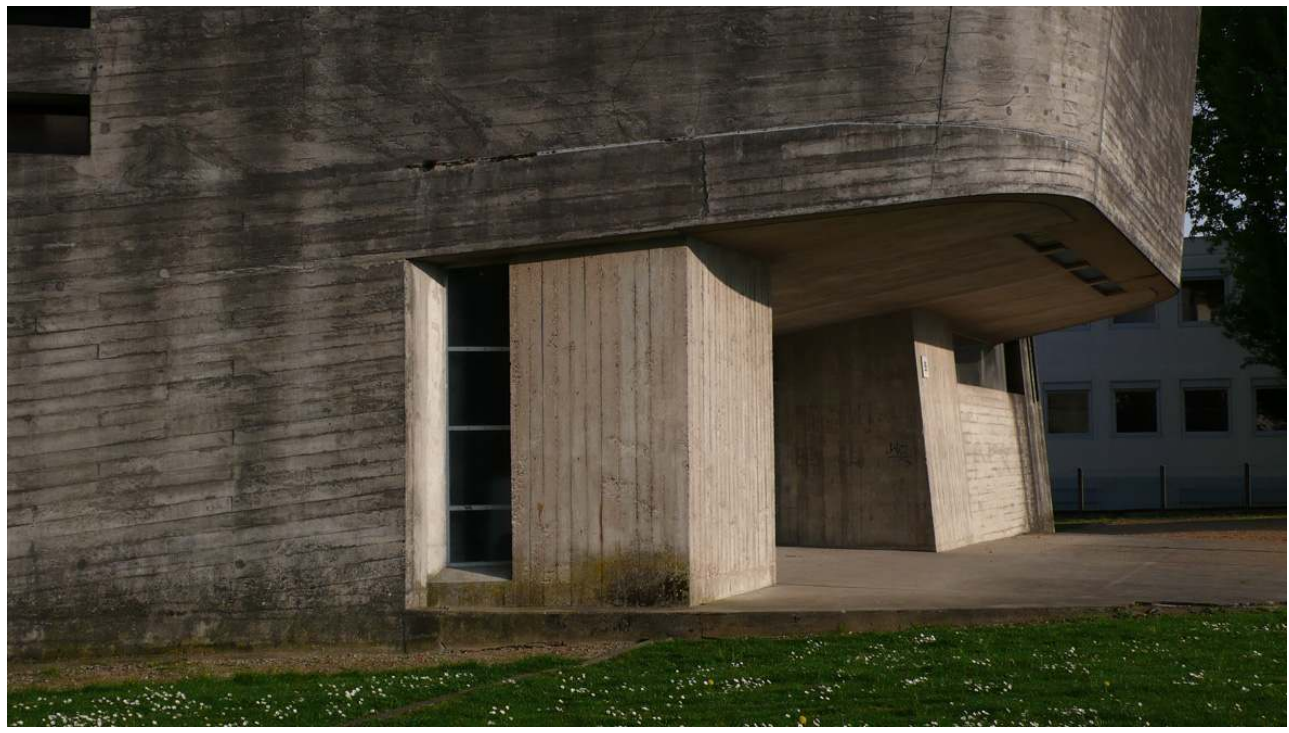

L'accès. Phot. Paul Barnoud.

(c) Atelier Cairn architectes.

\section{Questions soulevées par le projet de restauration}

56 L'église Sainte-Bernadette du Banlay est un édifice majeur de l'architecture d'aprèsguerre et la première application concrète des théories de ses auteurs sur la fonction oblique. 

auteurs entre intérieur et extérieur. Si l'extérieur de l'édifice présentait un aspect défensif, austère, l'intérieur, au contraire, devait apporter aux paroissiens un sentiment de bien-être et de protection. dégradation de l'église ne permet plus la perception de ce contraste. Les altérations extérieures ont certes renforcé l'aspect brut et agressif de cette architecture :

- les immeubles qui avaient été projetés à l'époque de sa construction ont été réalisés. Ils encadrent aujourd'hui l'édifice de tous côtés, réduisant l'espace de respiration de cette dernière ;

- les sols de ballast qui devaient entourer l'église ont été remplacés par du gazon ;

- les éclairages, intégrés à l'origine de façon discrète dans des blocs de béton brut le long du chemin principal, ont été détériorés ;

- les façades très noircies par la pollution ne permettent plus de lire la pureté des lignes du bâtiment.

accueillant conçu par Claude Parent et Paul Virilio présente aujourd'hui un aspect général dégradé, vétuste, sans doute un peu rebutant pour les utilisateurs.

61

Les infiltrations d'eau et les réagréages anarchiques ont donné au béton un aspect peu esthétique. Des traces de remontées salines et de rouille sont visibles un peu partout dans la nef, faisant craindre des désordres plus importants qu'il n'y paraît sur l'état des bétons. Les vitraux, cassés, ont peu à peu été remplacés par des plexiglas aujourd'hui opacifiés par les dépôts qui appauvrissent la qualité de la lumière. (fig. $\mathbf{n}^{\circ} \mathbf{3 7}, \mathbf{n}^{\circ} \mathbf{3 8}$ )

Figure 37

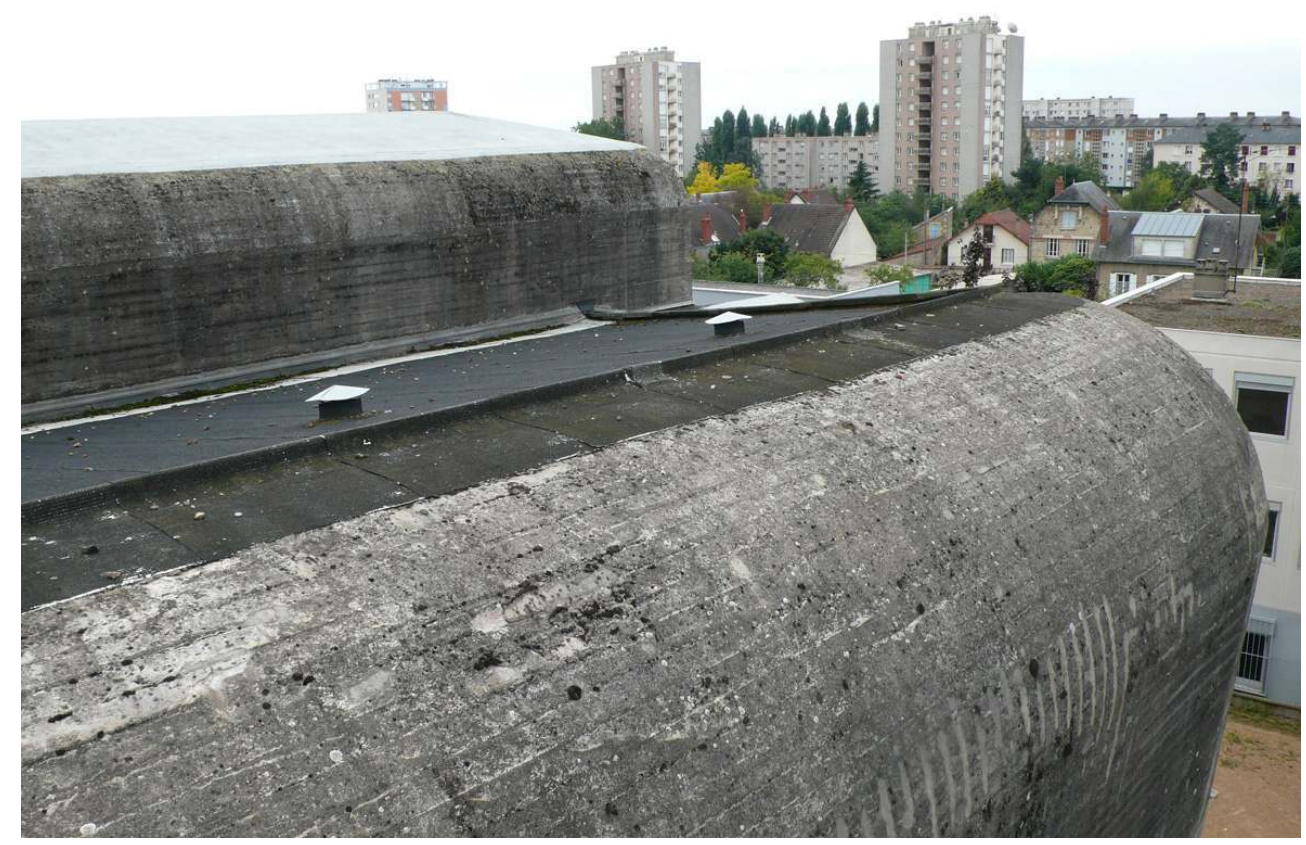

Étanchéité de la toiture et du lanternon. Phot. Paul Barnoud.

(c) Atelier Cairn architectes.

In Situ, 12 | 2009 


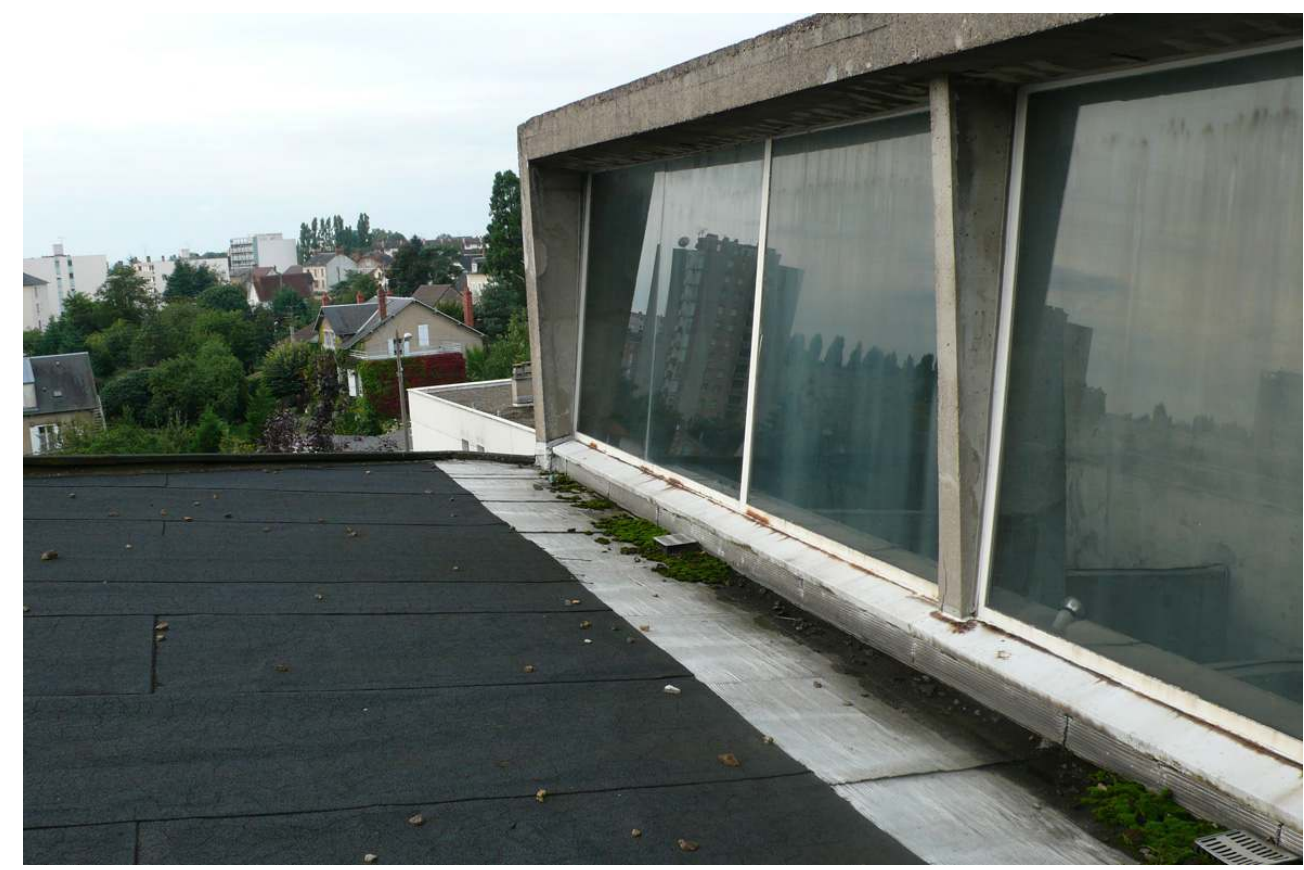

Prise de lumière du lanternon en toiture. Phot. Paul Barnoud.

(c) Atelier Cairn architectes.

62 La conséquence de ces dégradations semble avoir entraîné une réaction de ses utilisateurs qui s'évertuent à marquer leur appropriation du lieu, à l'habiter envers et contre tout, en l'adaptant, au jour le jour, au besoin de l'instant. Les différents dispositifs techniques et objets qui ont été peu à peu ajoutés altèrent sérieusement la lisibilité des volumes.

L'édifice d'apparence si puissant nous semble finalement assez vulnérable au passage du temps. Dans cette église on est toujours sur la frontière du presque rien, un mur de béton, un rayon de soleil qui passe par le lanternon ou les vitraux, des plans inclinés en plafond ou en sol, des pierres brutes sculptées. Il suffit de peu de choses, quelques coulées sur le béton, des plexiglas couverts d'algues ou quelques verres cassés pour que le charme soit sérieusement entamé.

Il en est des éléments constructifs comme du mobilier, il suffit d'un peu de pollution technique sur le plateau liturgique pour que toute la poésie de la conception se retrouve profondément altérée. Dans cette recherche du " presque rien », de l'essentiel, la moindre fausse note porte une atteinte profonde à l'édifice. Tout à coup, il n'est plus qu'une coquille vide, mal comprise, que l'on supporte faute de pouvoir la transformer radicalement. (fig. $n^{\circ} 39, n^{\circ} 40$ ) 
Figure 39

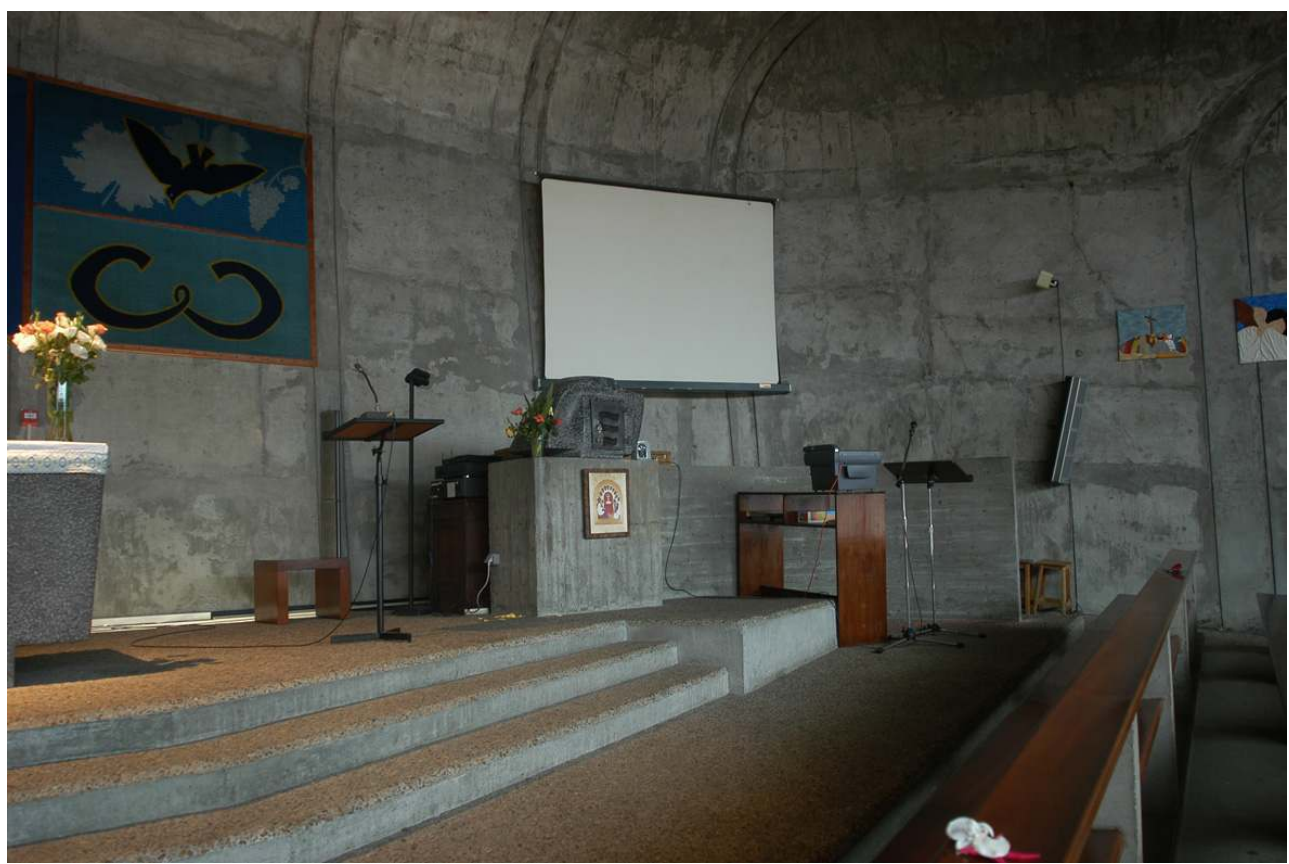

Le podium avec le tabernacle. Phot. Paul Barnoud.

(c) Atelier Cairn architectes.

\section{Figure 40}

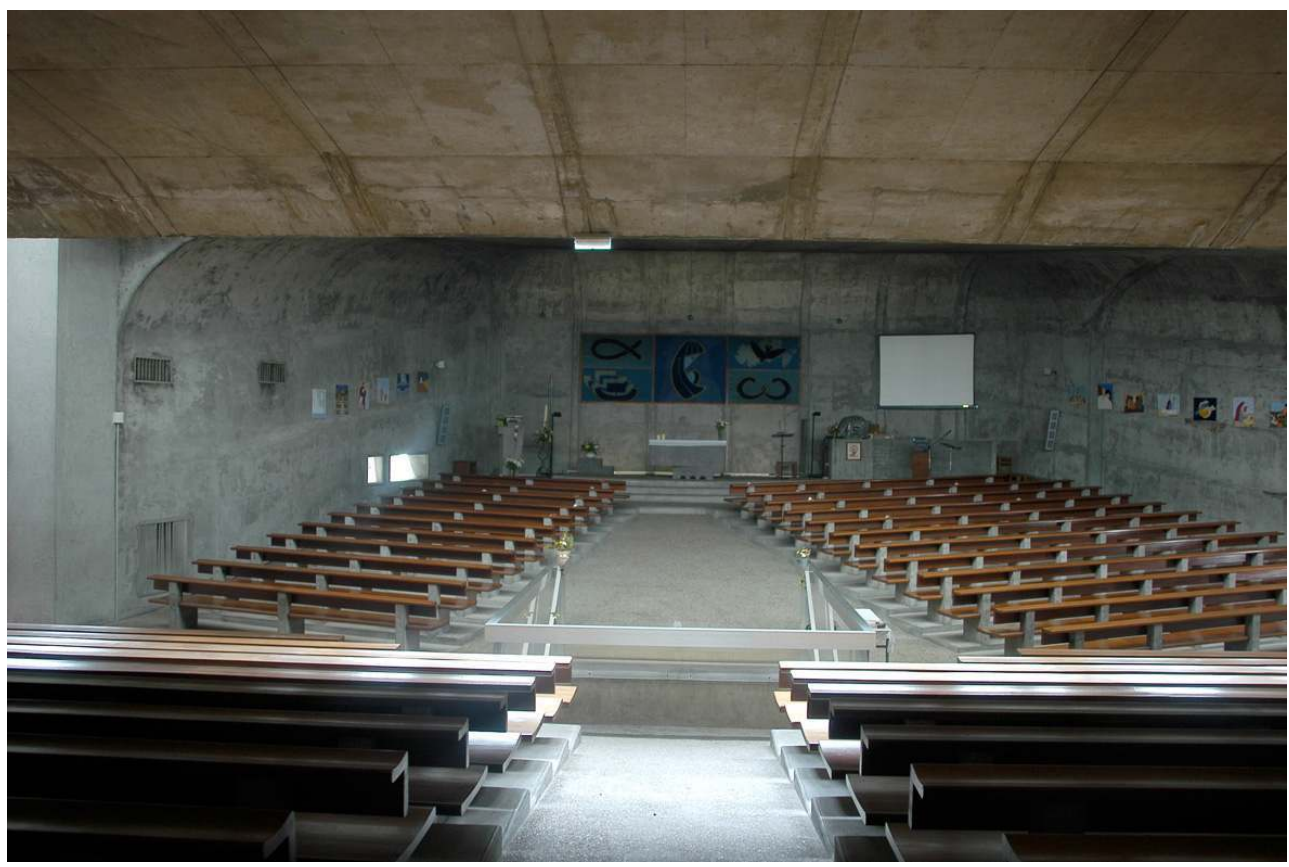

La salle d'assemblée. Phot. Paul Barnoud.

(c) Atelier Cairn architectes.

La restauration de Sainte-Bernadette du Banlay devrait permettre la préservation d'un édifice majeur de l'architecture du XXe siècle, mais aussi la redécouverte de ce patrimoine à travers la réappropriation de l'église par ses paroissiens et le clergé. Loin 
d'être un exercice de style, Sainte-Bernadette concrétise les nouveaux idéaux du concile Vatican II. D'une certaine façon, cet édifice singulier constitue pour l'Église catholique un défi, le défi de l'acceptation de sa propre histoire, de ses audaces dans la conquête de la modernité. (fig. $\mathrm{n}^{\circ} \mathbf{4 1}, \mathrm{n}^{\circ} \mathbf{4 2}$ )

Figure 41

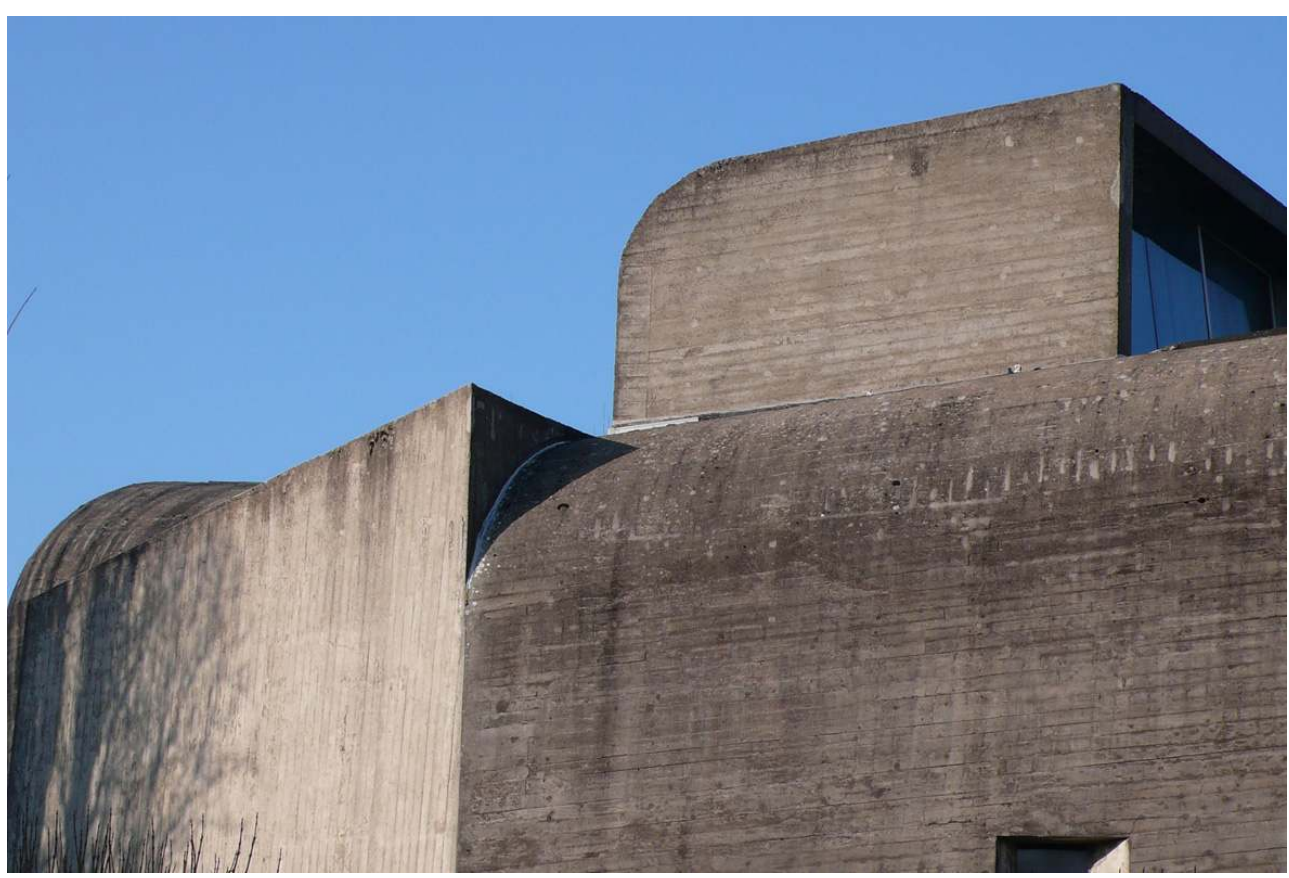

Imbrication du lanternon avec les coques. Phot. Paul Barnoud.

(c) Atelier Cairn architectes. 
Figure 42

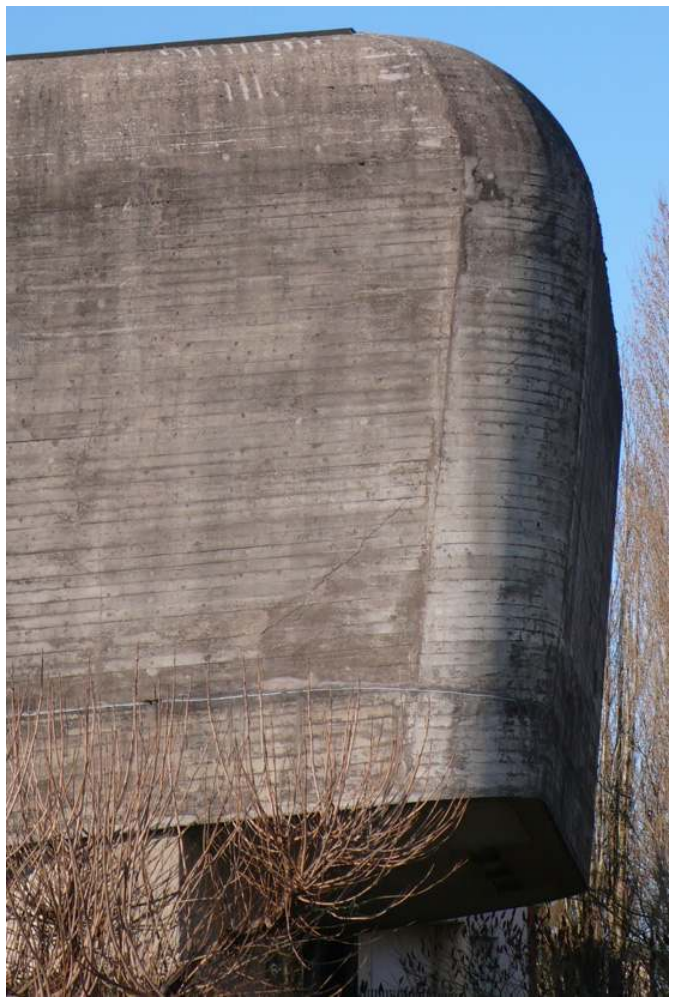

Traitement complexe du coffrage de l'angle incurvé. Phot. Paul Barnoud.

(c) Atelier Cairn architectes.

\section{NOTES}

1. Les plans originaux sont de Claude Parent, collection de l'abbé Bourgoing, consultables au CAUE de la Nièvre, contact : caue58@wanadoo.fr, www archi/CAUE58.

2. $40^{\mathrm{e}}$ anniversaire de la consécration de l'église Sainte-Bernadette. Nevers: Paroisse du Banlay, 2006.

3. JOLY, C. Claude Parent, Paul Virilio, église Sainte-Bernadette à Nevers. Paris : Éditions Jean-Michel Place, 2004, p. 13.

4. BOURGOIN, R. La naissance de la paroisse Sainte-Bernadette du Banlay et la construction de l'église, Bulletin de la société nivernaise des lettres, sciences et arts, $48^{\text {ème }}$ volume, Nevers, 1999, p. 164.

5. BOURGOIN, R. La naissance de la paroisse Sainte-Bernadette du Banlay et la construction de l'église, Bulletin de la société nivernaise des lettres, sciences et arts, $48^{\text {ème }}$ volume, Nevers, 1999, p. 166.

6. 1960, Le bunker de la Paix, Figaro, Paris, 14 septembre 2000. 
7. BOURGOIN, R. La naissance de la paroisse Sainte-Bernadette du Banlay et la construction de l'église, Bulletin de la société nivernaise des lettres, sciences et arts, $48^{\text {ème }}$ volume, Nevers, 1999, p. 168.

8. LOYER, François. L'église Sainte-Bernadette du Banlay à Nevers, A Nevers béton béni, L'œil, $\mathrm{n}$ - $147,1967$.

9. BOURGOIN, R. La naissance de la paroisse Sainte-Bernadette du Banlay et la construction de l'église, Bulletin de la société nivernaise des lettres, sciences et arts, $48^{\text {ème }}$ volume, Nevers, 1999, p. 166.

10. Église Sainte-Bernadette, Dossier Frac Centre.

11. Église Sainte-Bernadette, Dossier Frac Centre.

12. La Semaine Religieuse, Nevers, 1965.

13. Église Sainte-Bernadette, Dossier Frac Centre.

14. $40^{\mathrm{e}}$ anniversaire de la consécration de l'église Sainte-Bernadette. Nevers: Paroisse du Banlay, 2006.

15. JOLY, C. Claude Parent, Paul Virilio, église Sainte-Bernadette à Nevers. Paris : Éditions Jean-Michel Place, 2004, p. 7.

16. JOLY, C. Claude Parent, Paul Virilio, église Sainte-Bernadette à Nevers. Paris : Éditions Jean-Michel Place, 2004, p. 7.

17. 1960, Le bunker de la Paix, Figaro, Paris, 14 septembre 2000.

18. LOYER, François. L'église Sainte-Bernadette du Banlay à Nevers, A Nevers béton béni, L'œil, $n$ - $147,1967$.

19. VIRILIO, P. L'effet de capacité, Architecture Principe nº 9, décembre 1966.

20. Capellades, dans Guide des églises de France, Cerf 1969.

21. DEBIÈ, F. et VÉROT, P. Urbanisme et art sacré, une aventure du XXe siècle. Paris : Criterion histoire, 1991.

\section{RÉSUMÉS}

Construite par Claude Parent et Paul Virilio en 1964-1965, l'église Sainte-Bernadette du Banlay témoigne de leurs travaux sur la fonction oblique. L'édifice fut édifié à l'issue d'un concours d'architecture lancé en 1963 par Mgr Vial et l'Abbé Bourgoin, curé de la paroisse. L'église est inspirée de l'architecture des bunkers. Deux coques de béton s'imbriquent l'une dans l'autre en se décalant par rapport à l'axe longitudinal. L'apparence générale est un édifice monolithique, qui évoque un rocher. Á l'intérieur, deux grands plans obliques paraissent exhumés pour constituer la nef et le chœur. En relation étroite avec la grotte des apparitions de Lourdes, l'église est construite comme une crypte suspendue dont la coupe adopte la forme d'un cœur. Par le choix de matériaux bruts et d'un éclairage zénithal, les architectes confèrent à l'ensemble une étonnante intimité. C'est par l'opposition entre le volume extérieur austère et fermé et l'espace intérieur accueillant et protecteur que les concepteurs expriment la nouvelle fonction d'une église conçue dans une période d'incertitude et de tensions.

The Sainte-Bernadette du Banlay church at Nevers was built from 1964 to 1965 to the designs of the architects Claude Parent and Paul Virilio, working on their theme of the oblique function. It was the fruit of an architectural competition organised in 1963 by Monseigneur Vial and the Abbé Bourgoin, the parish priest. The church's architecture is inspired by that of defensive 
bunkers. Two reinforced concrete shells are joined the one into the other but out of true on a longitudinal axis. The overall appearance of the church is that of a monolithic block, something like a rock. Inside, two large oblique planes seem to emerge to create the nave and the chancel. Closely related to the Lourdes grotto of the Virgin's appearances, the church is designed as a suspended crypt which adopts the shape of a heart in its cross section. By using untreated concrete and sky lighting, the architects succeeded in giving an astonishing intimacy to the church. There is a striking opposition between the austere exterior volume and the welcoming and protective space inside. The architects expressed a new function for the church in an age of uncertainty and tension.

\section{INDEX}

Mots-clés : vitrail, Ambon, autel, architecture principe, baptistère, ballast, bunker, béton, béton brut, brutalisme, coques, église catholique, édifice cryptique, église fortifiée, fente de lumière, fonction oblique, grotte, guerre froide, hexagone, lanternon, plan incliné, plexiglas, structure, Vatican II

Keywords : stained glass, Ambon, altar, principle architecture, baptistery, ballast, bunker, concrete, raw concrete, Brutalism, shells, catholic church, cryptic church, fortified church, light slit, oblique function, grotto, cold war, hexagon, lantern, sloping plane, plexiglas, structure, Vatican II

\section{AUTEURS}

\section{CHRISTOPHE JOLY}

Architecte au CAUE de la Nièvre

\section{ORLANE BRAULT}

Historienne, documentaliste

\section{PAUL BARNOUD}

Architecte en chef des monuments historiques. Paul.barnoud@ateliercairn.fr 